\title{
Estimating the Impact of Arc Furnaces on the Quality of Power in Supply Systems
}

\section{Zbigniew Łukasik and Zbigniew Olczykowski *}

Faculty of Transport, Electrical Engineering and Computer Science, Kazimierz Pulaski University of Technology and Humanities, Malczewskiego 29, 26-600 Radom, Poland; z.lukasik@uthrad.pl

* Correspondence: z.olczykowski@uthrad.pl

Received: 11 February 2020; Accepted: 14 March 2020; Published: 20 March 2020

\begin{abstract}
Arc furnaces, due to their high unit power and load nature, belong to the receivers affecting the power quality. A dynamically changing electric arc is the main source of disturbances generated by arc devices. This current article presents the results of model tests of disturbances caused by arc furnaces. It also presents the attempts to estimate the power supply conditions for arc furnaces, so that they do not generate unacceptable disturbances to the power system. Various models of the electric arc are proposed. The values of the elements making up the furnace supply system were based on actual parameters. In these networks, measurements of electricity quality indicators were carried out, which allowed us to refer to the obtained results of model tests with the real values. Accordingly, to the real conditions, the values of the short-circuit power of the network and the power of furnace transformers were also adopted in the tests.
\end{abstract}

Keywords: model research; arc furnace; voltage fluctuations; unbalance

\section{Introduction}

The growing power of furnace transformers, resulting from the increase in furnace capacity and the shortening of melting time in the furnace, due to the use of secondary furnace steel treatment, cause that the arc furnaces' impact upon the power system is getting bigger. Arc furnaces belong to the group of so-called restless electricity consumers, which, as a result of the unstable operation of the electric arc the during melting of scrap metal, show rapid changes in power consumption, especially reactive power.

The estimation of disturbances caused by arc furnaces was carried out in two ways. In the networks supplying arc furnaces, a number of measurements of parameters characterizing the quality of the supplied voltage was conducted. Different power supply systems for steel mills were selected, which differed in the network short-circuit power, furnace transformer power and the number of arc devices operating in parallel. Figure 1 shows an example of the power supply system for one of the tested steelworks, together with the places where energy quality meters are connected. Measurements were carried out at several points simultaneously.

Based on the analysis of data recorded in the networks supplying arc devices, tests using various models of electric arc were conducted. Adoption of appropriate models was dependent on the type of disturbances caused by the arc furnace. The further part of the paper presents selected results of the measurements of electricity quality indicators and model tests. 


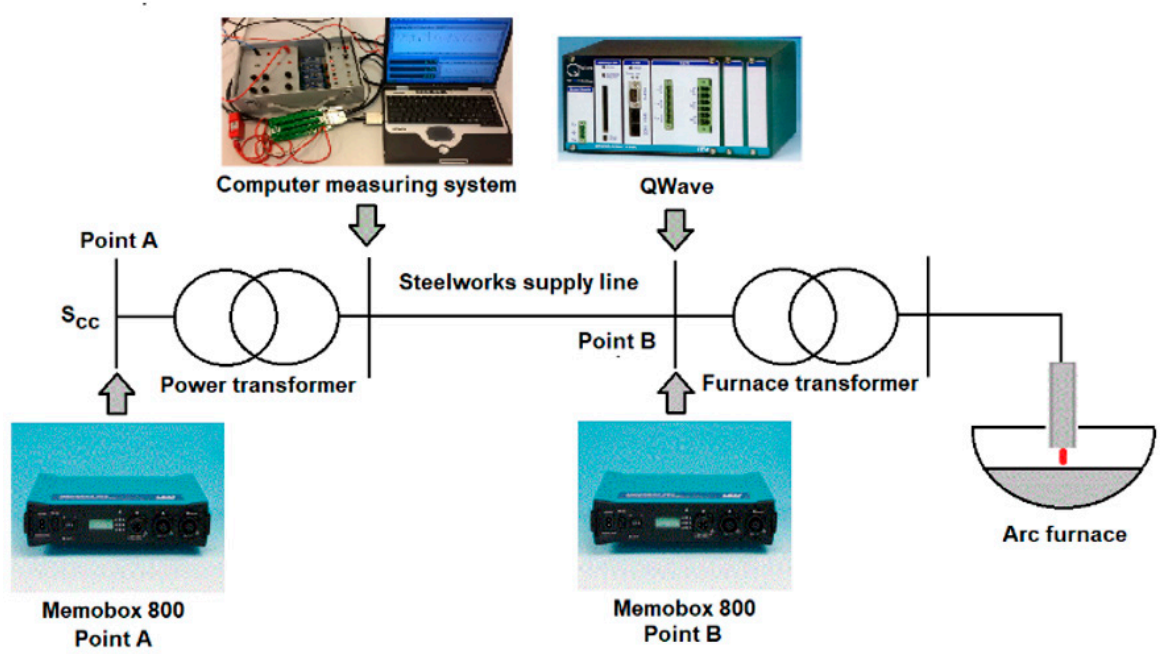

Figure 1. Places to measure indicators characterizing the quality of electricity.

Model tests are one way of assessing the quality of electricity in the power system. The use of computer simulations largely depends on the respective models of the electrical components that are part of the analyzed system. Due to the complex characteristic of the electric arc, it is very difficult to develop its deterministic model.

In the literature, many models of arc devices can be found, ranging from static ones, used e.g. for modeling the work of welding devices [1,2], through to the quasi-dynamic [3,4], and ending with dynamic models [5-9].

In the research using computer measuring techniques, the following models can be distinguished: one based on a series connected resistor and inductance $[10,11]$, the time-varying voltage source defined as a nonlinear function dependent on the length of the electric arc [12-15], and the classic based on nonlinear differential equations using Mayra equations and Cassie $[16,17]$. We should also mention the recently widely used simulation programs [18-26], including those based on neural networks [27-30].

The question may be asked, which of the arc models and methods of analysis is the most appropriate in the research on energy quality disturbances generated by arc devices? The results of many simulations are to a large extent similar to the real conditions that occur in networks supplying arc devices. However, this requires the use of complicated electric arc models and advanced simulation programs, hence, significantly limiting the practical application of these algorithms.

Therefore, there is a need to accept a compromise between the advanced level of the model, the accuracy of the results obtained, and their implementation in practical applications. Depending on the voltage distortion considered, it was proposed to use different models of electric arc, and to adopt appropriate arc furnace power supply systems.

\section{Voltage Fluctuations}

In the case of arc furnaces, we can talk about stochastic changes in both the amplitude and frequency of fluctuations, and the range of these changes is influenced by many factors. In the case of voltage fluctuations caused by arc furnaces, there is no periodicity of fluctuations, so it is used to determine the frequency of changes per unit of time, e.g., several changes per second. With the frequency of changes ranging from a few to a dozen or so per second, identifying and assessing voltage fluctuations caused by arc devices becomes an extremely complex issue.

To estimate voltage fluctuations at different voltage levels, measurements were carried out at two points: A: the steel mill power supply, HV; and B: the steel mill power supply, MV; as seen in Figure 1.

Voltage changes as defined in formula1 now represent the difference between the largest and smallest effective value recorded in the five-second measurement window, expressed as a percentage of the rated voltage $U_{\mathrm{N}}$. 
Voltage changes from $U_{\mathrm{A}}$ to $U_{\mathrm{B}}$ determine fluctuations:

$$
\Delta U=U_{\mathrm{A}}-U_{\mathrm{B}}
$$

or are expressed as a percentage of the supply voltage:

$$
\Delta U=\frac{U_{\mathrm{A}}-U_{\mathrm{B}}}{U_{\mathrm{N}}} 100 \%
$$

Steel mains supply voltage fluctuates between $90 \%$ and $104 \%$ of the rated voltage. The biggest fluctuations occur after turning the furnace on and after loading the next scrap bins. The range of voltage fluctuations in the $\mathrm{HV}$ network is $3.5 \% U_{\mathrm{N}}$ and in the MV network $14 \% U_{\mathrm{N}}$, with an attenuation factor between THE HV and MV of 0.8 , hence it can be assumed that the increase in voltage fluctuations is inversely proportional to the change in the short circuit power of the network, as shown in Figure 2.

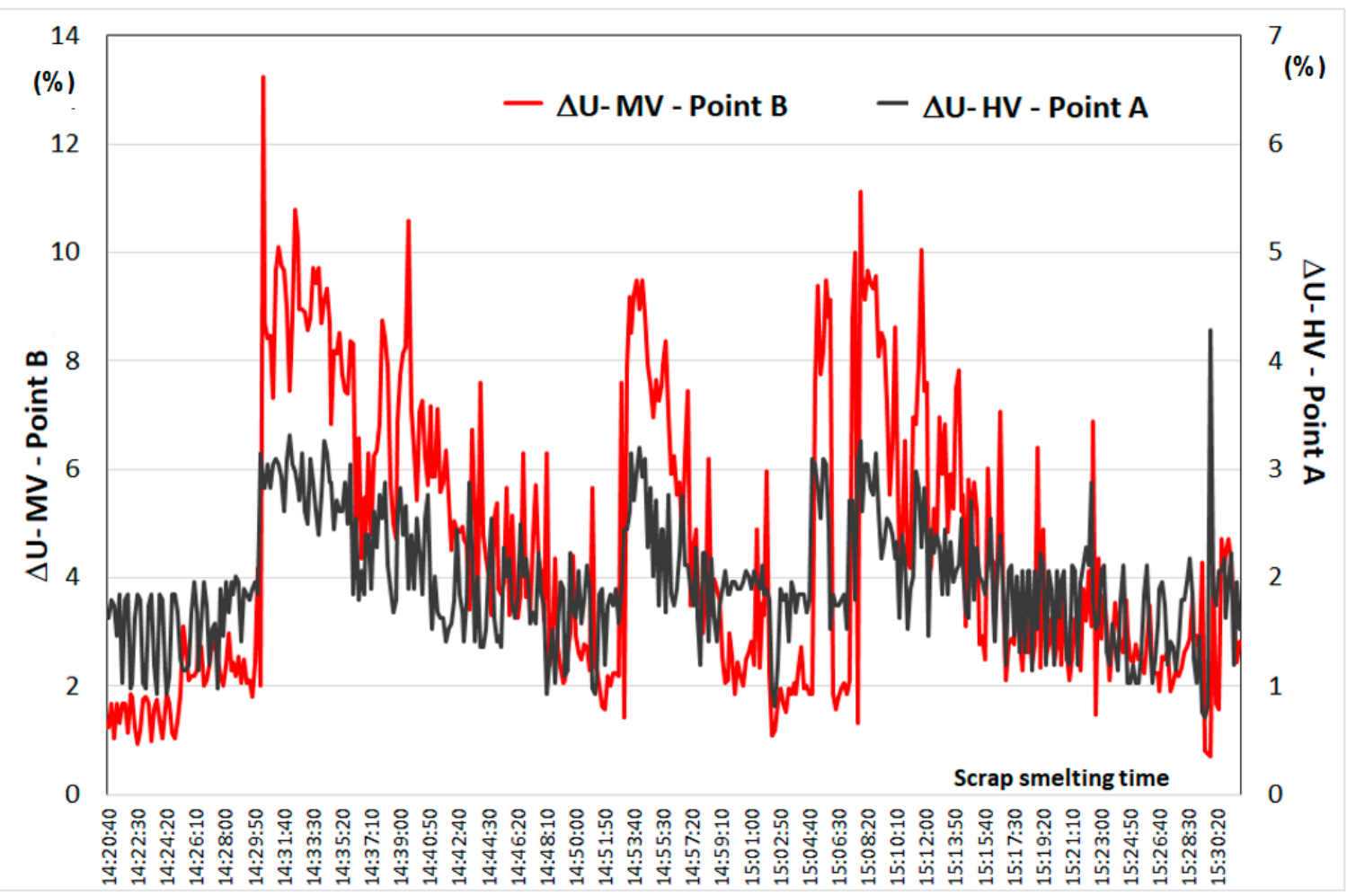

Figure 2. Voltage changes $\Delta U$ recorded during one melt: steelworks supply line: point A; steelworks supply line: point B.

Voltage fluctuations are propagated to the mains and other lines inside the smelter, including lighting circuits. Changes in the voltage supplying the lighting receivers cause changes in the luminous flux, which at a given amplitude and frequency of changes are perceived by the human eye, causing the negative effects described above.

Luminous flux changes resulting from voltage fluctuations are referred to as flashing light. Flicker is a phenomenon that is purely physiological. Voltage fluctuations, causing a perceptible flickering of light, are very difficult to determine objectively. Flicker, to which the eye of one person is sensitive, may be unnoticed by another person [31-36]. The type of light source may also play a fundamental role in the perception of flickering [37-41]. At a certain amplitude and frequency of changes in voltage fluctuations, flickering light causes nervousness in people, reaching the level of irritation, beyond which most people are not able to do any work related to the perception of objects of small dimensions, 
poorly contrasting with the surrounding background. In some cases, flickering can trigger epilepsy attacks [42].

It is reasonable to determine the relationship between voltage fluctuations and the severity of flickering light. Assuming that the frequency of voltage fluctuations generated by arc furnaces changes to a small extent, it can be stated that the increase in voltage fluctuations causes a proportional increase in light flickering. This thesis is confirmed by the results of the measurements of light flicker indicators and voltage fluctuations made in the network supplying arc furnaces.

Figure 3 presents changes in voltage fluctuations and the $P_{\text {st }}$ indicator recorded during melting in an arc furnace in the steel network supplying the steel plant (point B, Figure 1).

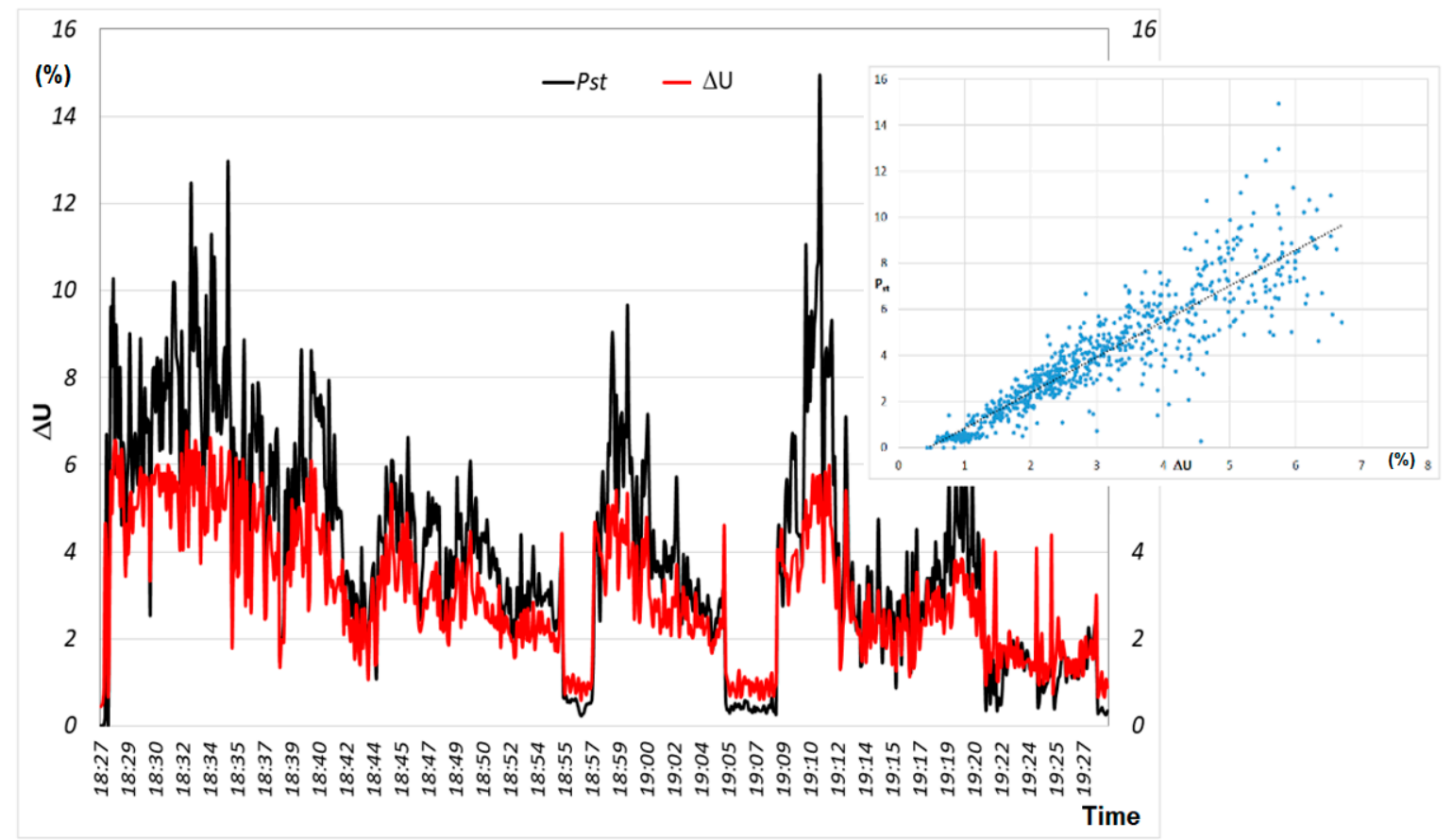

Figure 3. Changes in the short-term flicker indicator $P_{\text {st }}$ and changes in voltage $\Delta U$ during one smelting, line feeding steelworks: correlation coefficient $r \Delta U-\mathrm{P}_{\mathrm{st}}=0.90$.

Based on the analysis of the relationship between voltage changes and flicker indicators, it can be concluded that the increase in voltage changes causes a proportional increase in light flicker.

A single-phase substitute scheme is adopted in model tests for voltage fluctuations generated by arc furnaces. The adoption of such a scheme results from a large correlation of indicators characterizing the voltage distortion in individual phases $\left(\Delta U, P_{\mathrm{st}}, P_{l_{\mathrm{t}}}\right)$. For example, the correlation coefficients between indicators recorded during one melt in individual phases, are, respectively: for the short-term light flicker indicator: $r P_{\mathrm{st} 1}-P_{\mathrm{st} 2}=0.87, r P_{\mathrm{st} 2}-P_{\mathrm{st} 3}=0.90, r P_{\mathrm{st} 3}-P_{\mathrm{st} 1}=0.89$, and for the long-term light flicker indicator: $r P_{1 \mathrm{t} 1}-P_{\mathrm{lt} 2}=0.92, r P_{\mathrm{lt} 2}-P_{1 \mathrm{tt} 3}=0.94, r P_{1 \mathrm{t} 3}-P_{\mathrm{lt} 1}=0.93$, and for the voltage fluctuations: $r \Delta \mathrm{U}_{\mathrm{L} 1{ }^{-} \mathrm{L} 2}=0.95, r \Delta \mathrm{U}_{\mathrm{L} 2-\mathrm{L} 3}=0.93, r \Delta \mathrm{U}_{\mathrm{L} 3^{-} \mathrm{L} 1}=0.94$.

Figure 4 presents changes in the short-term light flicker $P_{\text {st }}$ index recorded in phases $\mathrm{L}_{1}, \mathrm{~L}_{2}, \mathrm{~L}_{3}$ during one melt in an arc furnace. 


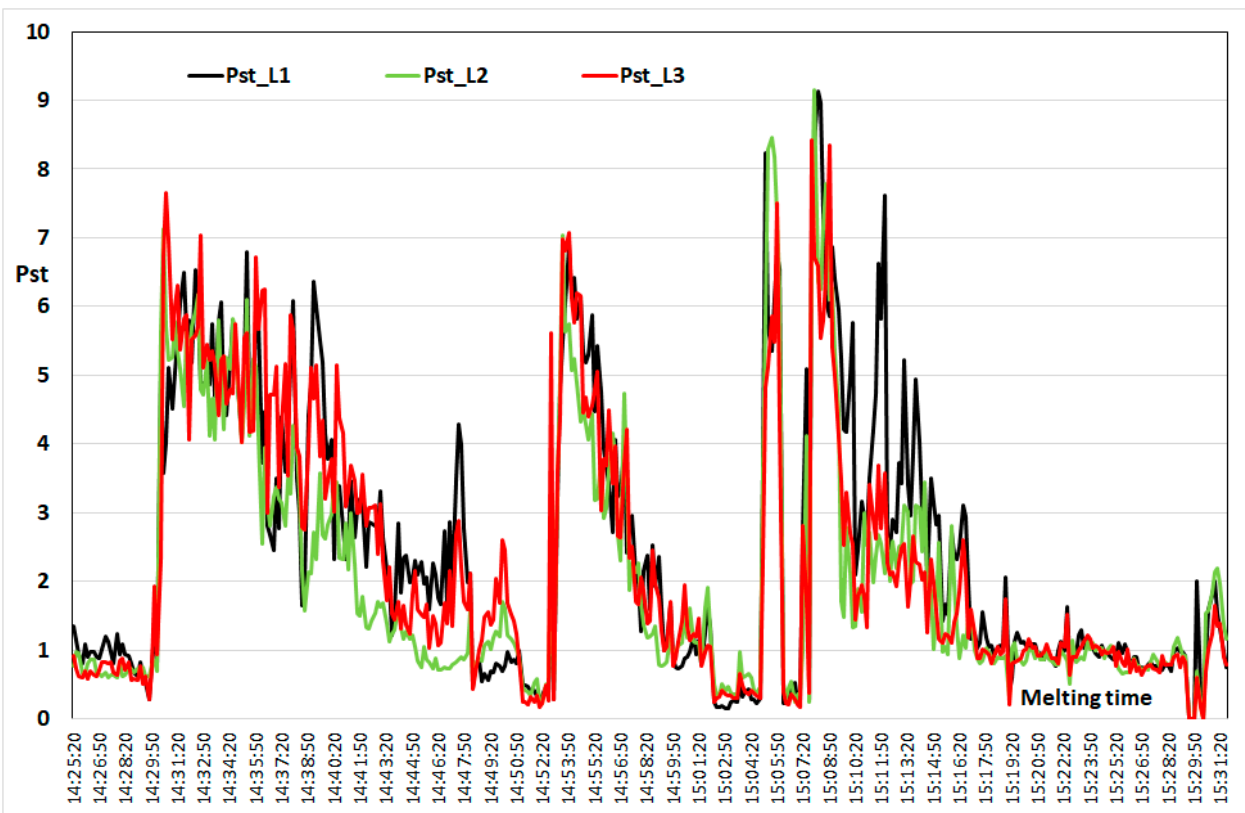

Figure 4. Short-term light flicker changes $P_{\text {st }}$ index recorded in phases $\mathrm{L}_{1}, \mathrm{~L}_{2}$ and $\mathrm{L}_{3}$.

A typical arc furnace power supply system is shown in Figure 5. The arc power supply system consists of the following elements: power supply line, often connecting the steel mill directly with the energy source (power plant); a power transformer at the main power supply point; the steel plant power supply line; and the furnace transformer with a high-current track.
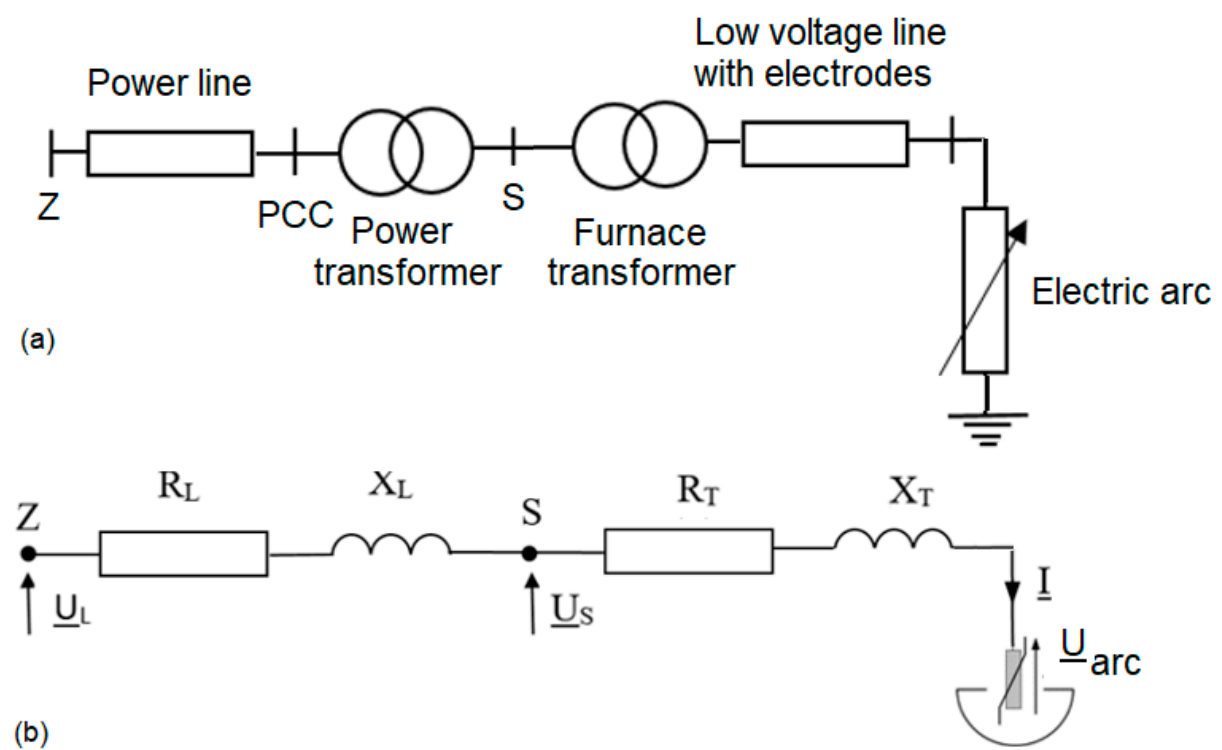

Figure 5. Arc furnace power supply (a) and its single-phase equivalent circuit $(\mathbf{b}) Z_{\mathrm{L}}$ : the power line impedance; $Z_{\mathrm{T}}$ : the high-current path impedance; $S_{\mathrm{cc}}$ : short circuit power of the network in PCC; $S_{\mathrm{ctr}}$ : power in three-phase short circuit electrodes with a charge; $U_{\text {arc }}$ : the arc voltage.

The supply voltage (source) $U_{\mathrm{L}}$ was adopted as a sinusoidal reference voltage of $U_{\mathrm{L}}=100 \%$, point $\mathrm{Z}$, as in Figure 5. The application of the measure expressed as a percentage allows for independence from the voltage value expressed in volts, occurring in different furnace supply systems. This also makes it easier to compare the results obtained from model tests to the acceptable levels of energy 
quality indicators; e.g., changes in the effective value, fluctuations, or voltage drops given in standards or legal regulations $[43,44]$.

The steel mill is supplied from a source with $U_{\mathrm{L}}$ voltage, via a power supply line with $R_{\mathrm{L}}$ resistance and $X_{\mathrm{L}}$ reactance. The impedance value of the smelter supply line reflects the supply conditions (short-circuit power) at the PCC point.

The arc furnace power supply system consists of $R_{\mathrm{T}}$ resistance and $X_{\mathrm{T}}$ reactance, determining the parameters of the high-current path together with the furnace transformer.

The electric arc was simulated using a sinusoidal voltage source with an amplitude depending on the arc length, which is the basic harmonic of the arc voltage. Such a model was adopted in [30].

The electric arc is represented by the $U_{\text {arc }}$ arc voltage. As already mentioned, the arc was simulated using an ideal sinusoidal voltage source with an amplitude depending on the arc length, which is the basic harmonic of the arc voltage.

In many publications, the electric arc of the arc furnace is replaced by a nonlinear resistance. In our publication, the electric arc has been replaced by a voltage depending upon the arc length. For example, when the furnace current is $I_{\mathrm{A}}$ (e.g. $80 \%$ of the furnace rated current), the arc voltage $U_{\mathrm{arc}}$ was calculated. When the current changed its value to another, e.g. $I_{\mathrm{B}}$ (e.g. $120 \%$ of the furnace's rated current), then the arc voltage was $U_{\text {arcB }}$. Knowing the $U_{\text {arcA }}$ and $U_{\text {arcA }}$ arc voltages, the $\Delta U_{\mathrm{AB}}$ voltage fluctuations were determined due to the change in the length of the electric arc, which is also associated with the change in the furnace current. This allowed a modeling the nonlinear nature of the electric arc. By analyzing the voltage fluctuations and voltage asymmetry, the authors adopted a constant value of its resistance $\mathrm{R}_{\mathrm{L}}$ and reactance $X_{\mathrm{L}}$ of the power supply network.

During the contact of the electrodes with the charge, the electric system supplying the furnace works in a short circuit. The amount of current is limited by the supply network impedance and high-current path impedance (including the furnace transformer impedance).

The short-circuit current can be determined by the formula (based on Figure 5b):

$$
I=\frac{U_{\mathrm{L}}}{\sqrt{\left(R_{\mathrm{L}}+R_{\mathrm{T}}\right)^{2}+\left(X_{\mathrm{L}}+X_{\mathrm{T}}\right)^{2}}}
$$

while the voltage supplying the steel plant, point S, as in Figure 5:

$$
U_{\mathrm{S}}=\sqrt{\left(R_{\mathrm{T}} I\right)^{2}+\left(X_{\mathrm{T}} I\right)^{2}}
$$

The electrodes must be shorted to the charge to ignite the electric arc. Raising the electrodes initiates the electric arc, which, however, burns unstably and goes out. This requires the electrodes to contact the charge again. This process is repeated several times until the arc ignites.

When the electrodes are connected to the charge, a very short circuit current flows through both the electrodes and the charge, which heats the electrodes at the point of contact with the scrap. In the event of a short circuit of the electrodes with the charge, there is a voltage drop in the steel mains supply network, which lasts until the electrodes are lifted (without the arc being initiated). The amount of current is limited by the supply network impedance, together with high-current path impedance (including the furnace transformer impedance).

Figure 6a presents changes in the RMS voltage recorded in the steel mains supply network during melting in the arc furnace. Figure $6 \mathrm{~b}$ illustrates the change in voltage in the network at the moment of arc initiation (short circuit and lifting the electrodes). The voltage then decreases below $90 \%$ Un. With the insufficient short-circuit power of the network in relation to the furnace power, the electric arc may not be initiated. 


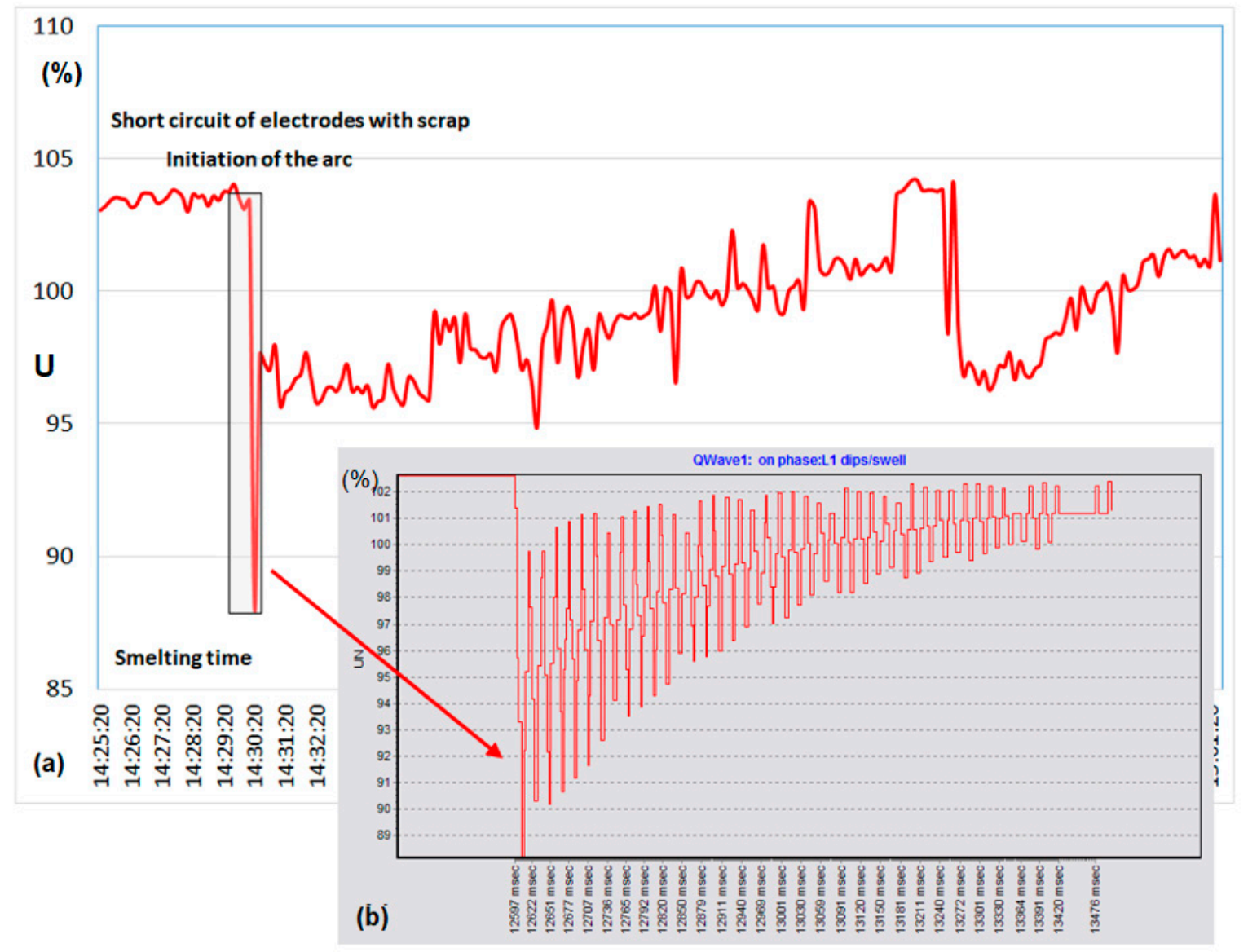

Figure 6. Voltage changes in the steel supply line (a) with indication of the electrode short-circuit period with charge $(\mathbf{b})$.

In arc furnaces, the largest current changes occur in the initial phase of casting, and after loading further baskets with scrap. The furnace changes its operating state from break to short circuit in the high-current circuit. Figure 7 shows the rapid voltage changes at $S$ (steelworks power supply), when the electrodes are shorted with the charge in the initial stage of casting. They were determined on the basis of model tests. Three cases are presented for three different short-circuit powers of the supply network, for which the ratio of the short-circuit power of the network to the power at short circuit of the electrodes with the charge is respectively: change of voltage waveform for $S_{\mathrm{cc}} / S_{\mathrm{ctr}}=140$ - Figure $7 \mathrm{~b}$ and $S_{\mathrm{cc}} / S_{\mathrm{ctr}}=20-$ Figure $7 \mathrm{c}$. Figure $7 \mathrm{~d}$ shows the changes in the RMS voltage when the electrodes are shorting with the charge. The short-circuit power values represent the actual parameters of the steel mains supply network. The PSpice program was used in model tests.

For a specific arc length, (which may change, e.g., due to the movement of the electrodes associated with the operation of the electrode position regulator, the sliding of melted scrap metal, movement of the arc over the electrode surface and charge, etc.)., a certain arc voltage occurs. The change in length causes a change in the arc voltage value, which has a direct effect on the furnace current.

The arc voltage can be determined by the formula:

$$
U_{\mathrm{arc}}=\sqrt{U_{\mathrm{L}}^{2}-I^{2}\left(X_{\mathrm{L}}+X_{\mathrm{T}}\right)^{2}}-I\left(R_{\mathrm{L}}+R_{\mathrm{T}}\right)
$$

After determining the arc voltage $U_{\text {arc }}$ you can determine the voltage value at the connection point of the furnace transformer, point $S$, as in Figure 5.

$$
U_{\mathrm{S}}=\sqrt{\left(U_{\mathrm{arc}}+R_{\mathrm{T}} I\right)^{2}+I^{2} X_{\mathrm{T}}^{2}}
$$


After ignition of the arc between the electrodes and the charge, as a result of changes in the arc length, the current changes its value dynamically, around the $I_{R}$ melting current (between points A-B) a pie chart, see Figure 8.

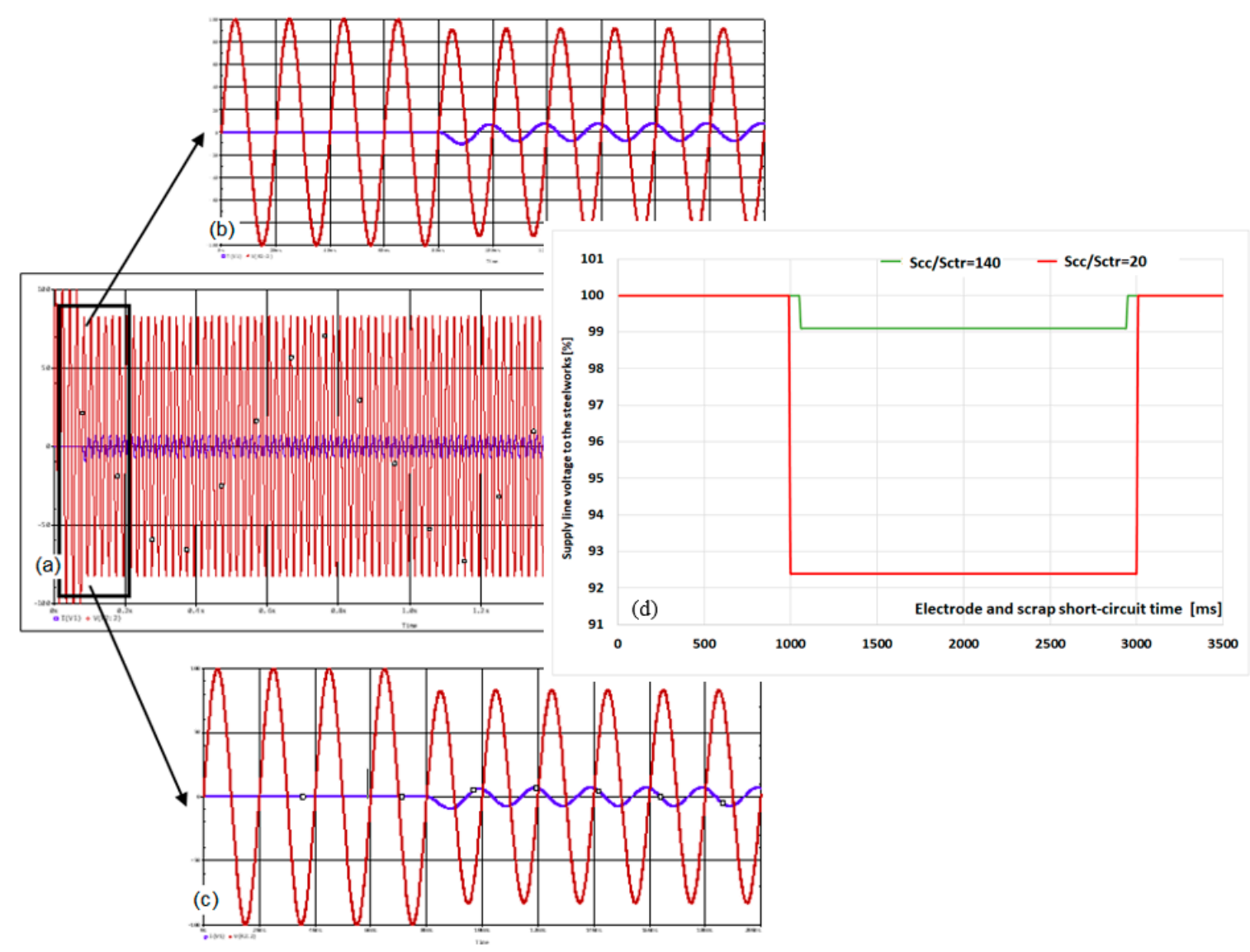

Figure 7. Voltage changes in the steel mains supply network recorded during the electrode short circuit with the charge (a) change of voltage waveform for $S_{\mathrm{cc}} / S_{\mathrm{ctr}}=140$ (b) change of voltage waveform for $S_{\mathrm{cc}} / S_{\mathrm{ctr}}=20$ (c) RMS voltage change $-S_{\mathrm{cc}} / S_{\mathrm{ctr}}=140$ and $S_{\mathrm{cc}} / S_{\mathrm{ctr}}=20$ (d) RMS voltage change for $S_{\mathrm{cc}} / S_{\mathrm{ctr}}$ $=140$ and $S_{\mathrm{cc}} / S_{\mathrm{ctr}}=20$.

The $U_{\operatorname{arcA}}$ and $U_{\mathrm{arcB}}$ arc voltages can be determined:

$$
\begin{aligned}
& U_{\mathrm{arcA}}=\sqrt{U_{\mathrm{L}}^{2}-I_{\mathrm{A}}^{2}\left(X_{\mathrm{S}}+X_{\mathrm{T}}\right)^{2}}-\left(R_{S}+R_{\mathrm{T}}\right) I_{\mathrm{A}} \\
& U_{\mathrm{arcB}}=\sqrt{U_{\mathrm{L}}^{2}-I_{\mathrm{B}}^{2}\left(X_{\mathrm{S}}+X_{\mathrm{T}}\right)^{2}}-\left(R_{\mathrm{S}}+R_{\mathrm{T}}\right) I_{\mathrm{B}}
\end{aligned}
$$

and voltages on at $I_{\mathrm{A}}$ and $I_{\mathrm{B}}$ :

$$
\begin{gathered}
U_{\mathrm{SA}}=\sqrt{\left(U_{\mathrm{arcA}}+R_{\mathrm{T}} I_{\mathrm{A}}\right)^{2}+I_{\mathrm{A}}^{2} X_{\mathrm{T}}^{2}} \\
U_{\mathrm{SB}}=\sqrt{\left(U_{\mathrm{arcB}}+R_{\mathrm{T}} I_{\mathrm{B}}\right)^{2}+I_{\mathrm{B}}^{2} X_{\mathrm{T}}^{2}}
\end{gathered}
$$

Voltage changes from $U_{\mathrm{SA}}$ to $U_{\mathrm{SB}}$ determine fluctuations in point $S$, Figure 5.

$$
\Delta U_{\mathrm{S}}=U_{\mathrm{SA}}-U_{\mathrm{SB}}
$$


or expressed as a percentage of the $U_{\mathrm{L}}$ reference voltage:

$$
\Delta U_{\mathrm{S}}=\frac{U_{\mathrm{SA}}-U_{\mathrm{SB}}}{U_{\mathrm{L}}} 100 \%
$$

or as a standard deviation voltage:

$$
D\left(U_{\mathrm{S}}\right)=\frac{\Delta U_{\mathrm{S}}}{2}
$$

In order to take into account changes in short-circuit power, which power has a decisive impact on the value of the voltage fluctuations, two power supply impedance values are adopted for model analysis, which correspond to two different ratios of the short-circuit power of the network to the furnace transformer power with short circuit electrodes, and are, respectively: 140, 20.

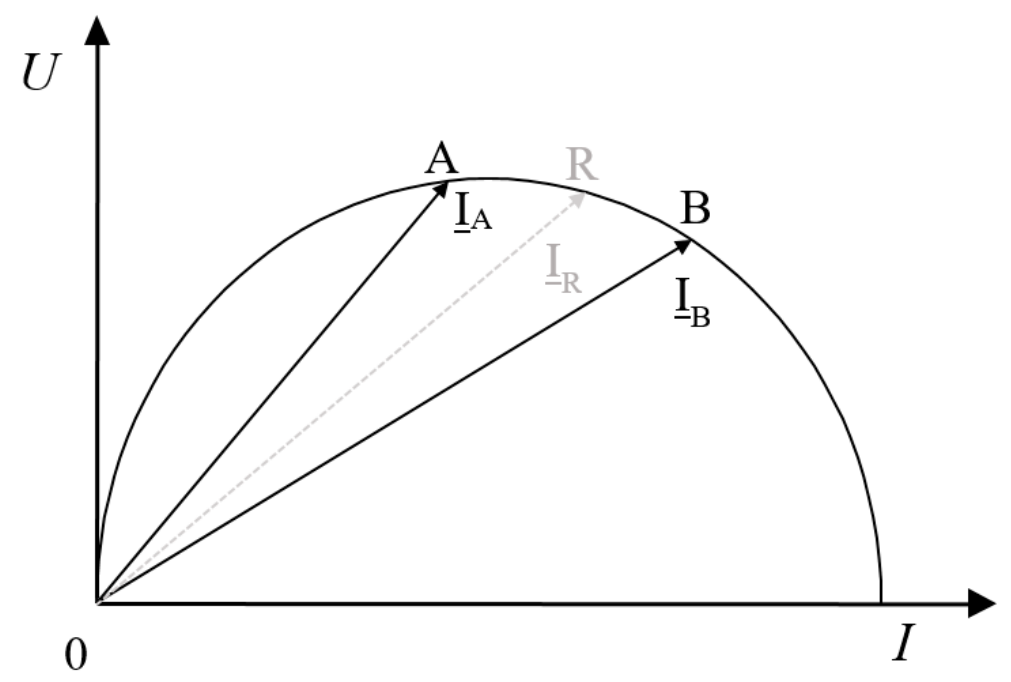

Figure 8. Circular chart of an arc device.

For arc furnaces, especially in the initial phase of melting scrap metal, there are dynamic changes in the current around the duty point set by the electrode control system. Assuming that the highest arc power used for melting scrap metal by the arc furnace is at a rated current of $I_{R}=100 \%$ In, the electrode position controller should ensure the furnace operation at a given optimal current, with points $\mathrm{A}$ and $\mathrm{B}$ depending on the short-circuit power of the supply network, from Figure 2. The changes in the length of the electric arc are so dynamic, that the regulator is not able to correct its settings in such a short time. The operating point of the furnace therefore changes between $\mathrm{A}^{\prime}$ and $\mathrm{A}^{\prime}$ for a network with the $S_{\mathrm{cc}} / S_{\mathrm{ctr}}$ ratio of 20 , and between $\mathrm{B}^{\prime}$ and $\mathrm{B}^{\prime}$ for the $S_{\mathrm{cc}} / S_{\mathrm{ctr}}=140$ network. Then a voltage fluctuation value corresponding to these changes $\Delta U_{\mathrm{A}^{\prime} \mathrm{A}^{\prime \prime}}$ and $\Delta U_{\mathrm{B}^{\prime} \mathrm{B}}$ is received - Figure 9.

Using the proposed model, it is also possible to determine the magnitude of voltage fluctuations at a different range of changes in the current consumed by the arc furnace and different short circuit power of the network and arc furnace power.

The conducted model tests and measurements carried out by the authors in the networks supplying arc devices show that the increase in voltage fluctuations for the analyzed case $\Delta U_{\mathrm{A}^{\prime} \mathrm{A}^{\prime \prime}} \Delta U_{\mathrm{B}^{\prime} \mathrm{B}^{\prime \prime}}=7.57$ is inversely proportional to the short-circuit ratio power $S_{\mathrm{ccB}} / S_{\mathrm{ccA}}=7$.

The decrease in the supply voltage to the $U_{S}$ steel mill results from the decrease in voltage at the network impedance, whereby the results. The results have been compared, taking into account and omitting the resistance in the circuit supplying the electric arc.

With sufficiently short-circuit power $\left(S_{\mathrm{cc}} / S_{\mathrm{ctr}}=140\right)$, the influence of arc supply resistance can be basically neglected. At low short-circuit power $\left(S_{\mathrm{cc}} / S_{\mathrm{ctr}}=20\right)$ for the melting current of $I_{\mathrm{R}}=100 \% \mathrm{I}_{\mathrm{N}}$, the difference in the steel supply voltage, taking into account and omitting the resistance, is about $0.4 \% U_{\mathrm{N}}-$ Figure 10 . 


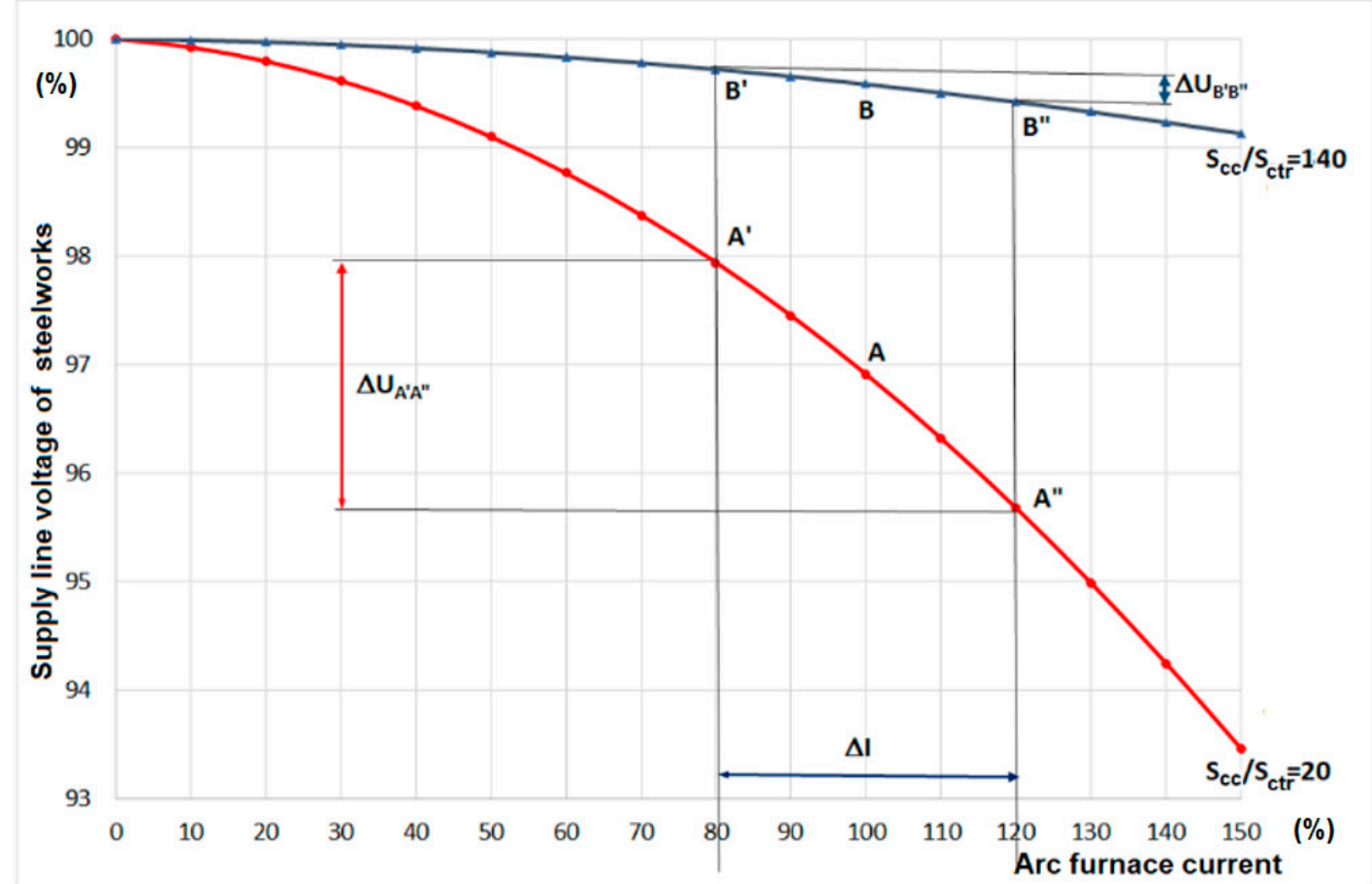

Figure 9. Voltage changes in the steel mains supply network for various short circuit power without line resistance.

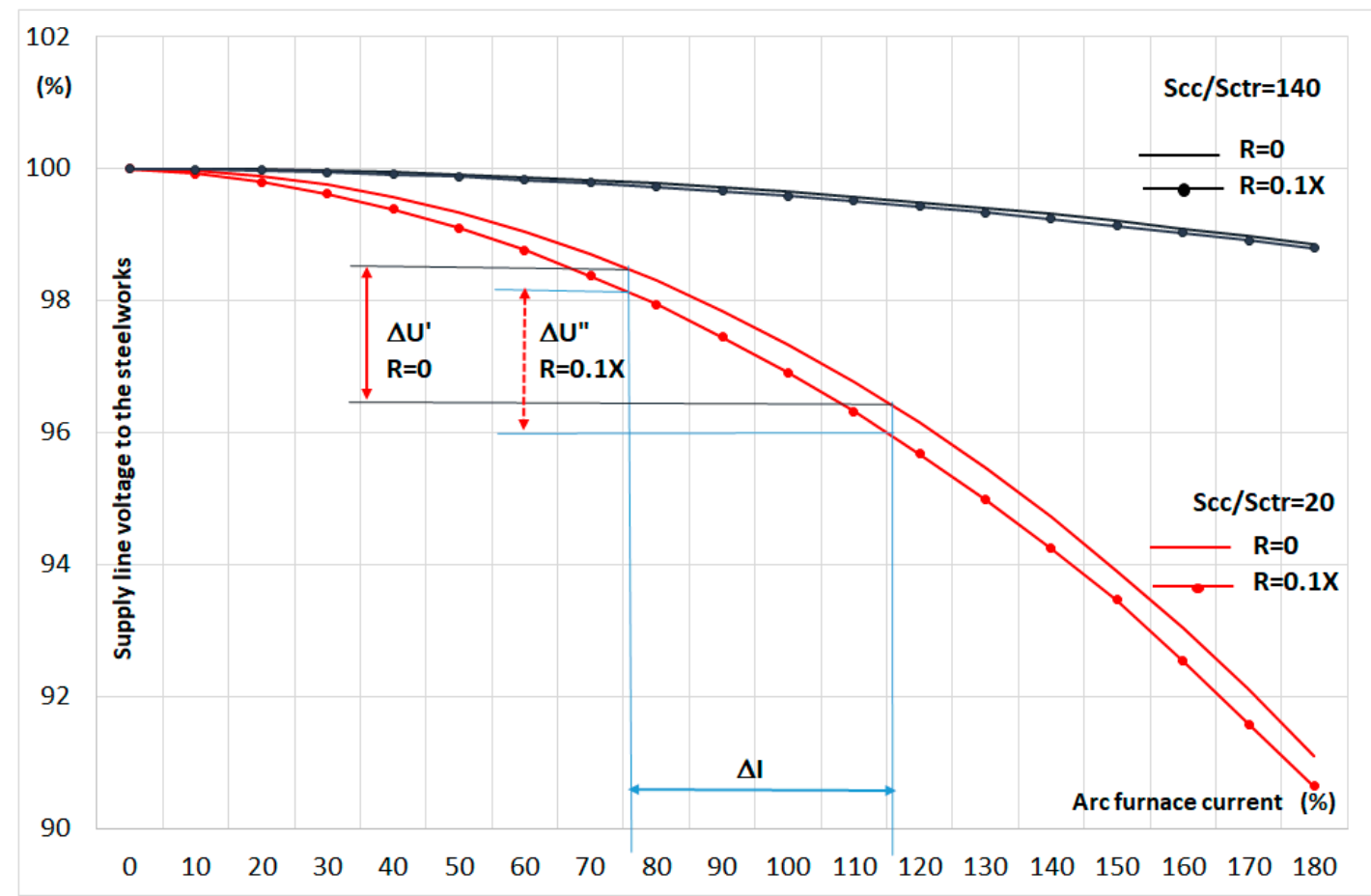

Figure 10. Voltage changes in the steel network supplying the electrodes with the charge short circuit.

The assumption of two-state current changes seems to be correct only for the initial stage of casting, and after loading the next bins with scrap. In order to take into account the changing current fluctuations at different melting periods, it was assumed that the current changes around the $\mathrm{I}_{R}$ (melting current) value, Figure 11. 


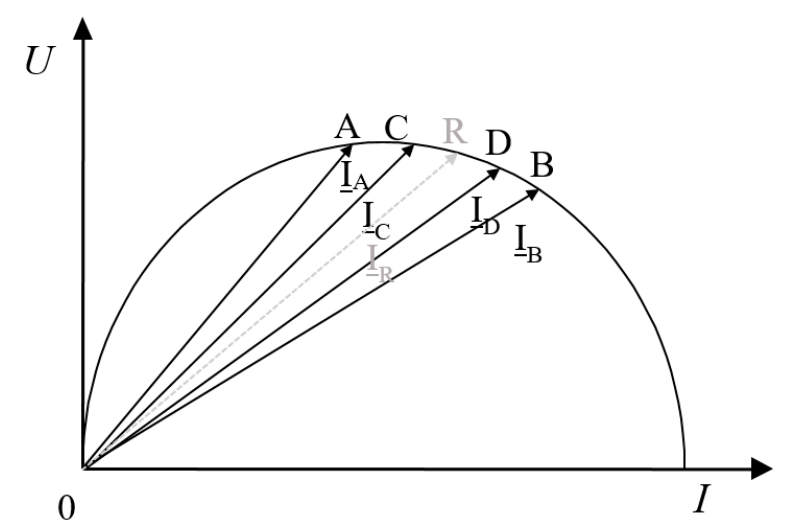

Figure 11. Circular chart for four levels of furnace current changes.

The arc voltages $U_{\mathrm{arcA}}, U_{\mathrm{arcB}}$ and $U_{\mathrm{arc}}, U_{\mathrm{arcD}}$ can be determined respectively:

$$
\begin{gathered}
U_{\mathrm{arcA}}=\sqrt{U_{\mathrm{L}}^{2}-I_{\mathrm{A}}^{2}\left(X_{\mathrm{S}}+X_{\mathrm{T}}\right)^{2}}-\left(R_{\mathrm{S}}+R_{\mathrm{T}}\right) I_{\mathrm{A}} \\
U_{\mathrm{arcB}}=\sqrt{U_{\mathrm{L}}^{2}-I_{\mathrm{B}}^{2}\left(X_{\mathrm{S}}+X_{\mathrm{T}}\right)^{2}}-\left(R_{\mathrm{S}}+R_{\mathrm{T}}\right) I \mathrm{~B} \\
U_{\mathrm{arcC}}=\sqrt{U_{\mathrm{L}}^{2}-I_{\mathrm{C}}^{2}\left(X_{\mathrm{S}}+X_{\mathrm{T}}\right)^{2}}-\left(R_{\mathrm{S}}+R_{\mathrm{T}}\right) I_{\mathrm{C}} \\
U_{\mathrm{arcD}}=\sqrt{U_{\mathrm{L}}^{2}-I_{\mathrm{D}}^{2}\left(X_{\mathrm{S}}+X_{\mathrm{T}}\right)^{2}}-\left(R_{\mathrm{S}}+R_{\mathrm{T}}\right) I_{D}
\end{gathered}
$$

and steel supply voltage at $I_{\mathrm{A}}, I_{\mathrm{B}}$ and $I_{\mathrm{C}}, I_{\mathrm{D}}$ :

$$
\begin{gathered}
U_{\mathrm{SA}}=\sqrt{\left(U_{\mathrm{arcA}}+R_{\mathrm{T}} I_{\mathrm{A}}\right)^{2}+I_{\mathrm{A}}^{2} X_{\mathrm{T}}^{2}} \\
U_{\mathrm{SB}}=\sqrt{\left(U_{\mathrm{arcB}}+R_{\mathrm{T}} I_{\mathrm{B}}\right)^{2}+I_{\mathrm{B}}^{2} X_{\mathrm{T}}^{2}} \\
U_{\mathrm{SC}}=\sqrt{\left(U_{\mathrm{arcC}}+R_{\mathrm{T}} I_{\mathrm{C}}\right)^{2}+I_{\mathrm{C}} X_{\mathrm{T}}^{2}} \\
U_{\mathrm{SD}}=\sqrt{\left(U_{\mathrm{arcD}}+R_{\mathrm{T}} I_{\mathrm{D}}\right)^{2}+I_{\mathrm{D}}^{2} X_{\mathrm{T}}^{2}}
\end{gathered}
$$

Based on the calculated $U_{\mathrm{SA}}, U_{\mathrm{SB}}, U_{\mathrm{SC}}, U_{\mathrm{SD}}$ voltages, the average voltage on the steel rail is:

$$
\bar{U}_{\mathrm{S}}=\frac{U_{\mathrm{SA}}+U_{\mathrm{SB}}+U_{\mathrm{SC}}+U_{\mathrm{SD}}}{4}
$$

average squares of $U_{\mathrm{S}}$ voltages:

$$
\overline{U_{\mathrm{S}}^{2}}=\frac{U_{\mathrm{SA}}^{2}+U_{\mathrm{SB}}^{2}+U_{\mathrm{SC}}^{2}+U_{\mathrm{SD}}^{2}}{4}
$$

and standard deviation $D\left(U_{\mathrm{S}}\right)$ :

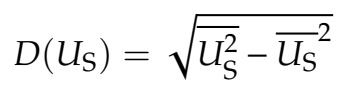

As the furnace steadily becomes more stable, currents with smaller ranges of change occur more often, up to a completely stable operation, when the arc device consumes a melting current of a fixed value $\left(I_{R}\right)$.

The probability of the occurrence of individual current values is determined in histograms, Figure 12, which correspond to different melting phases in the arc furnace. Histogram (a) corresponds 
to the operation of the furnace when the electrodes are shorted with the charge, whereas the (b)-(f) histograms characterize the current fluctuations from the largest in the initial melting period, to the stable operation of the furnace with a constant $\mathrm{I}_{\mathrm{R}}$ melting current, histogram $(\mathrm{g})$.
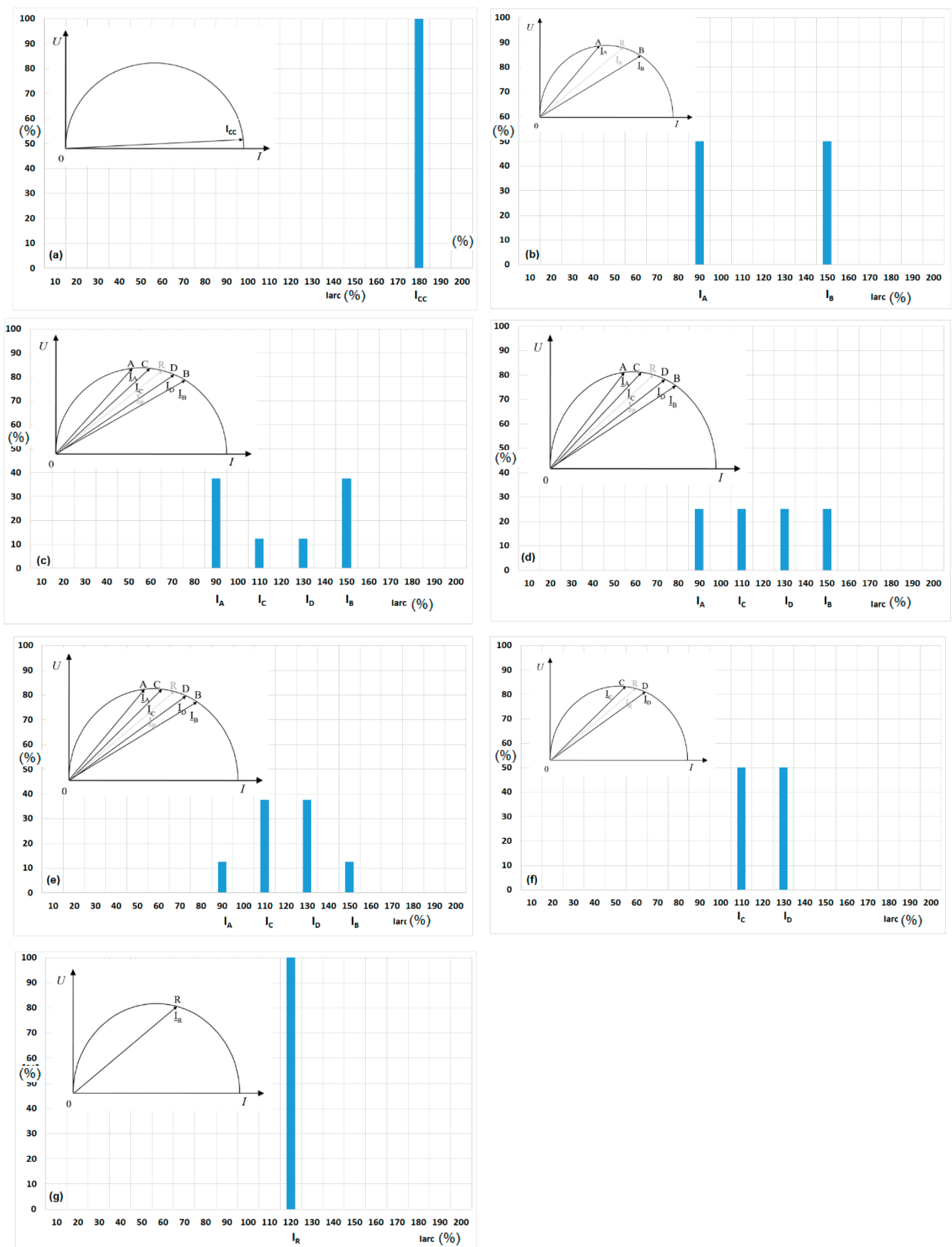

Figure 12. Histograms of furnace current changes: (a) electrode short circuit with charge, (b) two-state current changes - beginning of melting of scrap metal, (c-e) four-state current changes - for various furnace current fluctuations, (f) two-state current changes - final stage of melting scrap metal, (g) stable operation of the arc furnace. 
The maximum four-state current changes are shown above. A larger number of states (values) can be assumed in which the current consumed by the arc furnace will be located. This will enable a more accurate determination of the variability of voltage fluctuations during the melting.

Taking into account the impact of the furnace on the power system, however, the most important is the period when the changes of the current, together with voltage fluctuations, are the largest - Figure 13. The increase in voltage fluctuations resulting from arc devices switched in succession (Figure 14) is characterized by the $K_{N}$ factor. This factor determines the extent to which voltage fluctuations will increase with successively connected arc furnaces, with reference to the fluctuations arising during the operation of a single device (reference furnace). The $K_{N}$ voltage fluctuation coefficient is determined as the ratio of the $U_{\mathrm{S}}$ standard voltage deviation when operating $N$ furnaces $D(U S N)$, to the standard voltage deviation when operating single furnace $D(U S 1)$ :

$$
K_{2}=\frac{D\left(U_{\mathrm{SN}}\right)}{D\left(U_{\mathrm{S} 1}\right)}
$$

Respectively for the value of the short-term flicker index, $K_{N}$ can be determined from the formula:

$$
K_{\mathrm{N}}=\frac{P_{\mathrm{stN}}}{P_{\mathrm{st} 1}}
$$

where:

$P_{\mathrm{stN}}$ is the value of the short-term light flicker indicator recorded during the operation $N$ of arc furnaces, and $P_{\mathrm{st} 1}$ represents the value of the short-term light flicker indicator recorded during the operation of a single arc furnace.

According to the method proposed by UIE for the assessment of superposition of voltage fluctuations, the substitute parameter $P_{\text {st }}$ obtained with the use of the light flicker meter is assumed, and it is determined from the relationship $[45,46]$.

$$
P_{\mathrm{st}}=\sqrt[m]{P_{\mathrm{st}_{1}}^{m}+P_{\mathrm{st}_{2}}^{m}+\ldots+P_{\mathrm{st}_{n}}^{m}}
$$

where:

$P_{\text {stn }}$ corresponds to flicker level induced by n-th disrupting receiver

The value of the coefficient $\mathrm{m}$, occurring in the above formula, depends upon the characteristics of unquiet receivers, and can be categorized into five categories:

$m=4$ : used only for the summation of voltage changes due to arc furnaces specifically run to avoid coincident melts,

$m=3.2$ : this choice matches the slope of the straight part of the $P_{\mathrm{st}}=1$ curve,

$m=3$ : this is used for most types of voltage changes where the risk of coincident voltage occurring is small. The vast majority of studies combining unrelated disturbances will fall into this category, and it should be used where there is any doubt over the magnitude of the risk of coincident voltage changes occurring,

$m=2$ : this is used where coincident stochastic noise is likely to occur, e.g. coincident melts on arc furnaces,

$m=1$ : the resultant $P_{\text {st }}$ will approach the value given by this coefficient when there are very high occurrences of coincident voltage changes.

Analyzing the voltage fluctuation waveforms recorded at a different number of arc furnaces operating in parallel, it was found that in addition to the increase in the fluctuation amplitude, Figure $15 b$, a decrease in the average voltage value should also be taken into account, Figure 15a. Therefore, a method of determining the $K_{\mathrm{N}}$ factor has been developed, taking into account the change in average voltage value when switching on subsequent furnaces, the short circuit power of the network, furnace transformer power and the melting phase of the arc furnace [47]. 


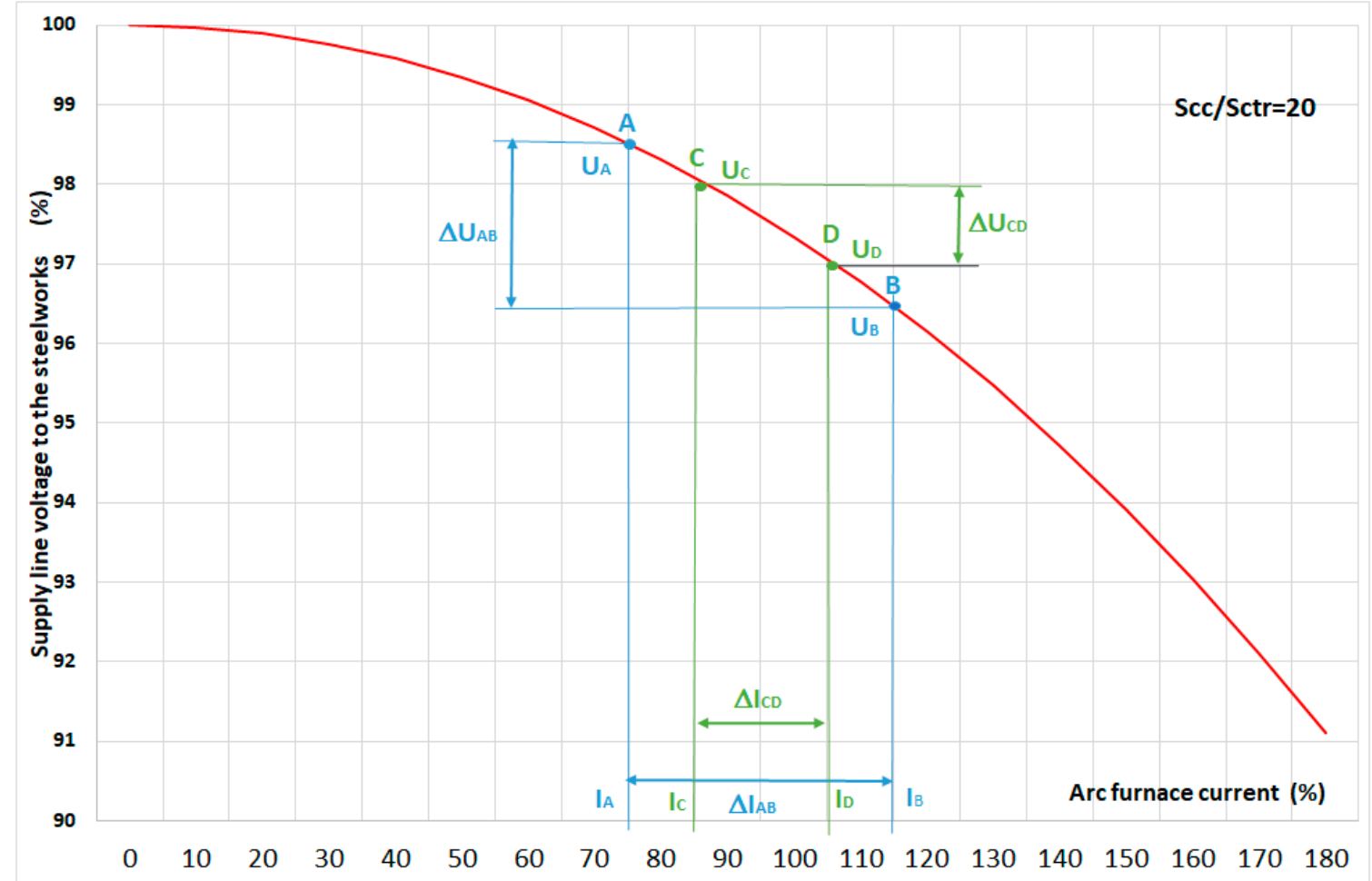

Figure 13. Voltage fluctuations for different histograms of furnace current changes: (b) and (f) from Figure 12.

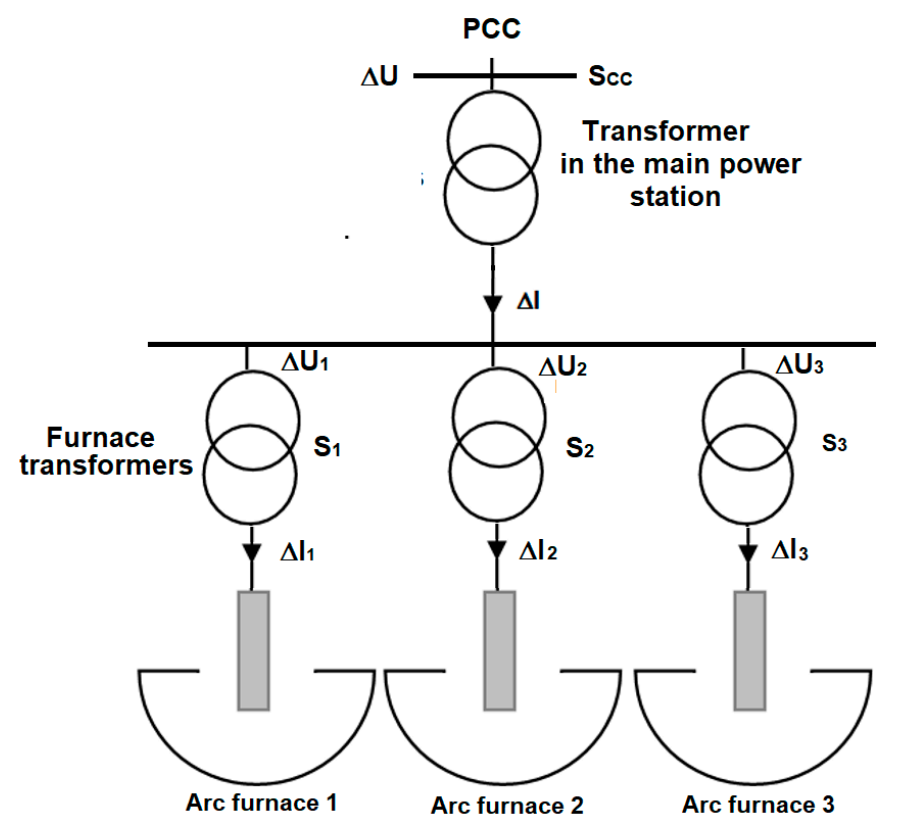

Figure 14. Power supply scheme for parallel working arc furnaces. 

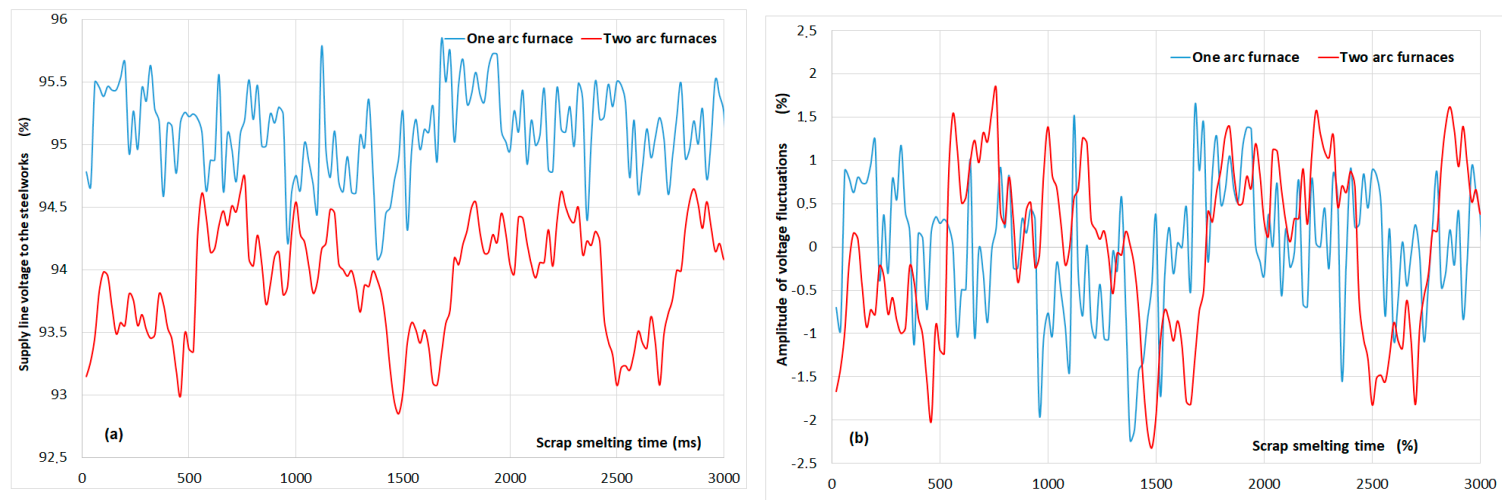

Figure 15. Voltage fluctuations in the steel network supplying the steelworks with different numbers of arc furnaces, (a) RMS value changes, (b) changes in the amplitude of voltage fluctuations.

On the basis of the developed power-voltage characteristics, the set of formulae allowing the determination of the coefficient $K_{N}$ were worked out [48]. The formula determining an increase in voltage fluctuations for arc devices being in the melting process can be expressed in the following form:

$$
K_{\mathrm{N}}=\frac{\sqrt{N}}{\sqrt{1+\frac{(N-1) k_{\mathrm{q}}^{\bullet} \overline{\bar{Q}_{1}}}{S_{\mathrm{CC}}}\left(\frac{U_{\mathrm{SN}}}{U_{\mathrm{S} 1}}\right)^{2}}}
$$

and for arc devices of different power:

$$
K_{\mathrm{N}}=\frac{\sqrt{\sum_{i=1}^{N r}\left(\frac{S_{\mathrm{ni}}}{S_{n 1}}\right)^{2}}}{\sqrt{1+\sum_{j=2}^{N}\left(\frac{k_{\mathrm{q}}^{\bullet} \overline{\mathrm{Q}_{\mathrm{j}}}}{S_{\mathrm{CC}}}\right)\left(\frac{U_{S \mathrm{~N}}}{U_{\mathrm{S} 1}}\right)^{2}}}
$$

Using the relationship determined for power-voltage characteristics, and replacing the arc by the voltage source formula (28) and (29) at identical devices, we can present the coefficient $K_{N}$ in the following form:

$$
K_{\mathrm{N}}=\frac{\sqrt{N}}{\sqrt{1+\frac{(N-1) k_{\mathrm{q}}^{*} S_{\mathrm{ctr} 1}}{S_{\mathrm{CC}}}\left(\frac{U_{S N}}{U_{\mathrm{S} 1}}\right)^{2}}}
$$

and at different devices:

$$
K_{\mathrm{N}}=\frac{\sqrt{\sum_{i=1}^{N r}\left(\frac{S_{\mathrm{ni}}}{S_{\mathrm{n} 1}}\right)^{2}}}{\sqrt{1+\sum_{j=2}^{N}\left(\frac{k_{\mathrm{q}}^{*} S_{\mathrm{ctrj}}}{S_{\mathrm{CC}}}\right)\left(\frac{U_{\mathrm{SN}}}{U_{\mathrm{S} 1}}\right)^{2}}}
$$

where:

- $\quad k_{q}^{\bullet} ; k_{q}^{*}$ - slope coefficients of the power-voltage characteristic calculated at a constant arc voltage and a constant arc resistance respectively,

- $\quad \bar{Q}_{j}$ - the mean reactive power drawn by j-th furnace,

- $\quad S_{\mathrm{cc}}$ - the short-circuit power on the bus-bars of the steelwork (in PCC furnaces),

- $S_{\mathrm{ctr}}$ - the shorting power of the arc device being exploited,

- $\quad S_{n i}$ - the nominal power drawn by i-th furnace, 
- $\quad U_{\mathrm{SN}} ; U_{\mathrm{S} 1}$ - the voltage on the bus-bars of the steelwork at the work of $N$ furnaces and the work of a single furnace (the furnace of the highest power, reference furnace) respectively.

Figure 16 presents changes in the value of the $K_{N}$ coefficient resulting from successively connected arc furnaces for two different short circuit powers of the supply network.

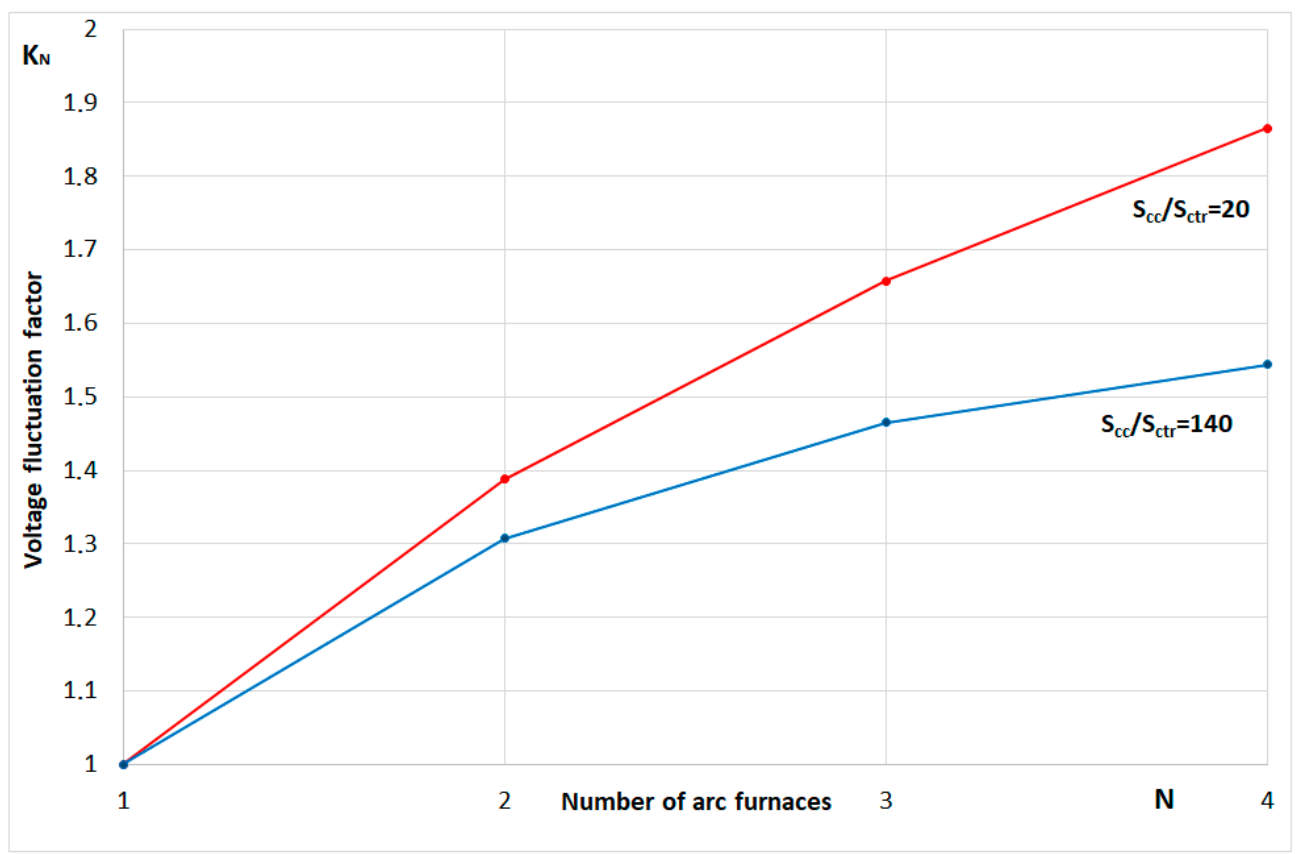

Figure 16. Change of $K_{\mathrm{N}}$ versus the $N$ number of identical arc furnaces.

At higher short-circuit power $\left(S_{\mathrm{cc}} / S_{\mathrm{ctr}}=140\right)$, the $\mathrm{K}_{\mathrm{N}}$ factor achieves higher values, which is due to, among others, less damping of voltage fluctuations by the power system. For lower short-circuit power $\left(S_{\mathrm{cc}} / S_{\mathrm{ctr}}=20\right)$, the increase in fluctuations resulting from arc furnaces operating in parallel is smaller, while the values of fluctuations caused by individual furnaces are much higher.

The presented method of assessing the increase in voltage fluctuations in parallel operations of arc devices has been confirmed by empirical tests carried out in several steel mills, both in terms of voltage fluctuations and flicker indicators. The steel works in which the measurements were carried out were selected in such a way as to represent different power conditions (different ratios of short-circuit power to the power of installed arc devices), various types of arc devices were used in them (different generations of arc furnaces) and the process of steel casting was different (e.g. the entire casting cycle takes place in an arc furnace or after melting, the blast furnace steel is used).

\section{Voltage Asymmetry}

The values of voltage and current asymmetry coefficients $\left(K_{2 \mathrm{U}}, K_{2 \mathrm{I}}\right)$ can be determined directly, based on measurements using, among others, power quality analyzers, as well as using various calculation methods. One of the basic methods used to analyze and evaluate asymmetry in three-phase circuits is the method of symmetrical components [49].

The complex voltage asymmetry coefficient can be expressed by the formula:

$$
\underline{K}_{2 \mathrm{U}}=\frac{\underline{U}_{2}}{\underline{\underline{U}}_{1}}=\frac{\underline{U}_{\mathrm{L} 12}+a^{2} \underline{U}_{\mathrm{L} 23}+a \underline{U}_{\mathrm{L} 31}}{\underline{U}_{\mathrm{L} 12}+a \underline{U}_{\mathrm{L} 23}+a^{2} \underline{U}_{\mathrm{L} 31}}=\frac{U_{2}}{U_{1}} e^{j \psi_{u}}
$$

In practical applications, there is often no need to consider the angle $\psi_{u}$, the phase shift angle between the compatible and opposite components (in the reference phase) and for the assessment of asymmetry it is assumed: 
Voltage asymmetry factor:

$$
K_{2 \mathrm{U}}=\frac{\left|\underline{\mathrm{U}}_{\mathrm{L} 12}+a^{2} \underline{U}_{\mathrm{L} 23}+a \underline{U}_{\mathrm{L} 31}\right|}{\left|\underline{U}_{\mathrm{L} 12}+a \underline{U}_{\mathrm{L} 23}+a^{2} \underline{U}_{\mathrm{L} 31}\right|}=\frac{U_{2}}{U_{1}}
$$

One of the basic documents defining the method of measuring asymmetry (as well as other parameters of electricity quality) is EN 61000-4-30 [50]. The value of the asymmetry coefficient is determined by the formula:

$$
K_{2 U}=\sqrt{\frac{1-\sqrt{3-6 \beta}}{1+\sqrt{3-6 \beta}}} 100 \%
$$

where the auxiliary term $\beta$ is given by the formula:

$$
\beta=\frac{U_{\mathrm{L} 12}^{4}+U_{\mathrm{L} 23}^{4}+U_{\mathrm{L} 31}^{4}}{\left(U_{\mathrm{L} 12}^{2}+U_{\mathrm{L} 23}^{2}+U_{\mathrm{L} 31}^{2}\right)^{2}}
$$

In IEC 61000-2-12 [51], the asymmetry factor is determined by the formula:

$$
K_{2 U}=\sqrt{\frac{6\left(U_{\mathrm{L} 12}^{2}+U_{\mathrm{L} 23}^{2}+U_{\mathrm{L} 31}^{2}\right)}{\left(U_{\mathrm{L} 12}+U_{\mathrm{L} 23}+U_{\mathrm{L} 31}\right)^{2}}-2}
$$

while, in IEC 61000-2-1 [52], ANSI C84.1 [53] and ER P29 [54]:

$$
K_{2 \mathrm{U}}=\frac{\Delta U_{\max }}{U_{\text {ave }}} 100 \%
$$

where:

$\Delta U_{\max }$ - maximum deviation of the phase voltage from the average value $U_{\text {ave }}$ - average value of three phase voltages.

In Gost 13109-97 [55], the consistent and opposite components are determined from the formulas:

$$
\begin{aligned}
& U_{1}=\sqrt{\frac{1}{12}\left(\left[\left(\sqrt{3} U_{\mathrm{L} 12}+\sqrt{\left.4 U_{\mathrm{L} 23}^{2}-\left(\frac{U_{\mathrm{L} 23}^{2}-U_{\mathrm{L} 31}^{2}}{U_{\mathrm{L} 12}}+U_{\mathrm{L} 12}\right)^{2}\right)^{2}+\left(\frac{U_{\mathrm{L} 23}^{2}-U_{\mathrm{L} 31}^{2}}{U_{\mathrm{L} 12}}\right)^{2}}\right]\right.\right.} \\
& U_{2}=\sqrt{\frac{1}{12}\left(\left[\left(\sqrt{3} U_{\mathrm{L} 12}-\sqrt{\left.4 U_{\mathrm{L} 23}^{2}-\left(\frac{U_{\mathrm{L} 23}^{2}-U_{\mathrm{L} 31}^{2}}{U_{\mathrm{L} 12}}+U_{\mathrm{L} 12}\right)^{2}\right)^{2}+\left(\frac{U_{\mathrm{L} 23}^{2}-U_{\mathrm{L} 31}^{2}}{U_{\mathrm{L} 12}}\right)^{2}}\right]\right.\right.}
\end{aligned}
$$

and the asymmetry factor:

$$
K_{2 \mathrm{U}}=\frac{\sqrt{\frac{1}{12}\left[\left(\sqrt{3} U_{\mathrm{L} 12}-\sqrt{4 U_{\mathrm{L} 23}^{2}-\left(\frac{U_{\mathrm{L} 23}^{2}-U_{\mathrm{L} 31}^{2}}{U_{\mathrm{L} 12}}+U_{\mathrm{L} 12}\right)^{2}}\right)^{2}+\left(\frac{U_{\mathrm{L} 23}^{2}-U_{\mathrm{L} 31}^{2}}{U_{\mathrm{L} 12}}\right)^{2}\right]}}{\sqrt{\frac{1}{12}\left[\left(\sqrt{3} U_{\mathrm{L} 12}+\sqrt{4 U_{\mathrm{L} 23}^{2}-\left(\frac{U_{\mathrm{L} 23}^{2}-U_{\mathrm{L} 31}^{2}}{U_{\mathrm{L} 12}}+U_{\mathrm{L} 12}\right)^{2}}\right)^{2}+\left(\frac{U_{\mathrm{L} 23}^{2}-U_{\mathrm{L} 31}^{2}}{U_{\mathrm{L} 12}}\right)^{2}\right]}} 100 \%
$$

A nomogram is a graph with which you can quickly and without calculations get an approximate solution to a particular equation. In the Kowzan method, described in publication [56], the asymmetry 
coefficient is read from the nomogram after determining the voltage ratios $U_{\mathrm{L} 23}, U_{\mathrm{L} 31}$ to $U_{\mathrm{L} 12}$, Formula (39):

$$
\frac{A_{\mathrm{C}}}{A_{\mathrm{A}}}=\frac{U_{\mathrm{L} 31}}{U_{\mathrm{L} 12}} \quad \frac{A_{\mathrm{B}}}{A_{\mathrm{A}}}=\frac{U_{\mathrm{L} 23}}{U_{\mathrm{L} 12}}
$$

Another method using nomograms (the method of the Institute of Energy of Ukraine) [56] allows determining the voltage asymmetry coefficient with an absolute error that does not exceed $0.1 \%$, and similarly to the Kowzan method, the relationships between individual voltage values are used: Formula (40).

$$
x=\frac{U_{\mathrm{L} 12}}{U_{\mathrm{L} 31}} \quad y=\frac{U_{\mathrm{L} 21}}{U_{\mathrm{L} 31}}
$$

Arc furnaces also cause voltage asymmetry. In the case of arc furnaces, the source of asymmetry is changing the arc resistance, which causes currents flowing in individual phases to have different values. It is also possible to deliberately introduce current asymmetry for furnaces with an asymmetrical design, which is to achieve the symmetry of the heating power in individual phases. The causes of voltage asymmetry can be divided into two groups: those resulting from the structural asymmetry of arc devices (construction asymmetry), as well as from the asymmetry arising during the melting in the arc furnace (operational asymmetry). The asymmetry of furnace currents affects the power supply network (causing voltage asymmetry) and the operation of a furnace itself. The assessment of voltage asymmetry in the arc power supply line can be made on the basis of an analysis of the asymmetry index measurement results, or based on calculated values. Due to the fact that the magnitude of the voltage asymmetry changes during melting, the assessment of the asymmetry based upon data obtained from measurements with electricity quality parameters meters seems to be the best method. However, one should take into account errors that may arise in the measuring path (indirect measurement using current and voltage transformers). In relation to the values adopted, as in [56] as a reference, the asymmetry coefficient measured by means of electricity quality parameters meters is on average higher by $4.07 \%$ (Table 1$)$. The values of voltage and current asymmetry coefficients $\left(K_{2 \mathrm{U}}, K_{2 \mathrm{I}}\right)$ can be determined directly, based on measurements using, among others, electricity quality analyzers, as well as using various calculation methods. The method proposed by the author made it possible to determine voltage asymmetry based on a differential factor and differential angle.

Table 1. The values of the asymmetry coefficient determined by various methods.

\begin{tabular}{cccccccccc}
\hline \multicolumn{2}{c}{$\begin{array}{c}\text { Voltage (\%) } \\
\text { Measurement }\end{array}$} & & \multicolumn{9}{c}{$\mathbf{K}_{\mathbf{2 u}}$} \\
\cline { 3 - 10 } & & Measurement & $\begin{array}{c}\text { IEC } \\
\mathbf{6 1 0 0 0 - 1 - 1 2}\end{array}$ & $\begin{array}{c}\text { IEC } \\
\mathbf{6 1 0 0 0 - 4 - 3 0}\end{array}$ & $\begin{array}{c}\text { IEC 61000-1-1 } \\
\text { ANSI C84.1 }\end{array}$ & $\begin{array}{c}\text { Gost } \\
\mathbf{1 3 1 0 9 - 9 7}\end{array}$ & Nomogram & \multirow{2}{*}{ Autor } \\
\hline $105.85 ;$ & $103.31 ;$ & 104.68 & 1.45 & 1.40 & 1.40 & 1.25 & 1.35 & 1.41 & 1.37 \\
\hline $103.15 ;$ & $101.41 ;$ & 102.77 & 0.95 & 1.03 & 1.03 & 1.01 & 0.99 & 1.01 & 1.02 \\
\hline $103.94 ;$ & $101.73 ;$ & 102.97 & 1.34 & 1.24 & 1.24 & 1.17 & 1.20 & 1.31 & 1.23 \\
\hline $101.47 ;$ & $101.36 ;$ & 101.96 & 0.40 & 0.36 & 0.36 & 0.35 & 0.38 & 0.36 & 0.36 \\
\hline
\end{tabular}

For the $U_{\mathrm{L} 12}, U_{\mathrm{L} 23}, U_{\mathrm{L} 31}$ voltages, the average square value of these $U^{2}$ ave voltages will be calculated:

$$
U_{\mathrm{ave}}^{2}=\frac{1}{3}\left(U_{\mathrm{L} 12}^{2}+U_{\mathrm{L} 23}^{2}+U_{\mathrm{L} 31}^{2}\right)
$$

$W_{\mathrm{U}}^{2}$ asymmetry differential module:

$$
W_{\mathrm{U}^{2}}=\frac{\sqrt{2}}{3} \sqrt{\left(U_{\mathrm{L} 12}^{2}-U_{\mathrm{L} 23}^{2}\right)^{2}+\left(U_{\mathrm{L} 23}^{2}-U_{\mathrm{L} 31}^{2}\right)^{2}+\left(U_{\mathrm{L} 31}^{2}-U_{\mathrm{L} 12}^{2}\right)^{2}}
$$

and differential angle: 


$$
\alpha_{\mathrm{U}^{2}}=\operatorname{arctg} \frac{U_{\mathrm{L} 23}^{2}-U_{\mathrm{L} 31}^{2}}{\sqrt{3}\left(2 U_{\mathrm{L} 12}^{2}-U_{\mathrm{L} 23}^{2}-U_{\mathrm{L} 31}^{2}\right)}+\left[1-\operatorname{sign}\left(2 U_{\mathrm{L} 12}^{2}-U_{\mathrm{L} 23}^{2}-U_{\mathrm{L} 31}^{2}\right)\right] \cdot 90^{\circ}
$$

Then the asymmetry differential coefficient was determined: $k_{\mathrm{U}}^{2}$ :

$$
k_{\mathrm{U}^{2}}=\frac{W_{\mathrm{U}^{2}}}{U_{\mathrm{ave}}^{2}}=\sqrt{2} \frac{\sqrt{\left(U_{\mathrm{L} 12}^{2}-U_{\mathrm{L} 23}^{2}\right)^{2}+\left(U_{\mathrm{L} 23}^{2}-U_{\mathrm{L} 31}^{2}\right)^{2}+\left(U_{\mathrm{L} 31}^{2}-U_{\mathrm{L} 32}^{2}\right)^{2}}}{\left(U_{\mathrm{L} 12}^{2}+U_{\mathrm{L} 23}^{2}+U_{\mathrm{L} 31}^{2}\right)}
$$

On the basis of the differential coefficient $\mathrm{k}_{\mathrm{U}}{ }^{2}$, the voltage asymmetry coefficient is determined from the formula:

$$
K_{2 \mathrm{U}}=\frac{\sqrt{1-k_{\mathrm{U}^{2}}^{2}}-1}{k_{\mathrm{U}^{2}}}
$$

In the case of small voltage asymmetry, the formula (47) can be approximated:

$$
K_{2 \mathrm{U}} \approx 0.5 k_{\mathrm{U}^{2}}
$$

Table 1 presents the values of voltage asymmetry coefficients measured in the steel supply network and determined by various methods. Additionally, voltage asymmetry coefficients determined by different methods were compared with those presented by Kowalski in [56]. The asymmetry coefficient determined according to [50,51] based on the formula [52,53] is burdened with the largest error amounting to a maximum of $14.6 \%$ (average $7.47 \%$ ) in relation to the reference values. The method of differential coefficients proposed by the author allows for the determination of the asymmetry coefficient with an average error, compared to the reference values, on average $0.87 \%$, which is similar to the error in the method presented in Gost 13109-97 [55], at 0.94\%.

Similarly, as in the case of voltage fluctuations, the magnitude of the asymmetry arising in the supply network of arc devices, apart from the current asymmetry, is also influenced by the amount of power consumed by the furnace in relation to the short-circuit power of the supply network, which can be written with the formula:

$$
K_{2 \mathrm{U}}=K_{2 \mathrm{I}} \frac{1.1 S_{\mathrm{n}}}{S_{\mathrm{cc}}}
$$

where:

$K_{2 I}$ is the current asymmetry factor

$S_{\mathrm{n}}$ is the rated apparent power of an arc furnace

$S_{\mathrm{cc}}$ is the short circuit power of the supply network

Based on the measurements carried out in the networks supplying arc furnaces, it was found that the current asymmetry coefficient rarely exceeds the value of 30\% [57].

Assuming that the asymmetry factor should not exceed 1\% for $110 \mathrm{kV}$ lines and $2 \%$ for $110 \mathrm{kV}$ lines, it is possible to determine the ratio of the rated furnace power to the short circuit power of the network at which an unacceptable voltage asymmetry will not occur [44].

For the connection groups I-II, the relationship can be presented:

$$
0.3 \frac{1.1 S_{\mathrm{n}}}{S_{\mathrm{cc}}} \leq 0.01
$$

which corresponds to:

$$
\frac{S_{\mathrm{n}}}{S_{\mathrm{cc}}} \leq 0.03
$$

For connection groups III-VI: 


$$
0.3 \frac{1.1 S_{\mathrm{n}}}{S_{\mathrm{cc}}} \leq 0.02
$$

and respectively:

$$
\frac{S_{\mathrm{n}}}{S_{\mathrm{cc}}} \leq 0.06
$$

In monograph [56], the author presents a relationship that should be met, so that a single-phase receiver can be connected to the network, without the need to install any symmetrization devices:

$$
S_{\mathrm{cc}} \geq \frac{k S_{\mathrm{n}}}{K_{2 \mathrm{U}}}
$$

Assuming that the voltage asymmetry factor should not exceed $2 \%$ and $\mathrm{k}=1.1$, the short-circuit power should be more than 60 times higher than the receiver's power.

Structural asymmetry is associated with the construction of multi-current circuits feeding an arc furnace. The high-current track is designed to supply electricity to a charge. Knowledge of the high-current path parameters allows for the determination of the arc operating characteristics. These characteristics show the relationship between basic electrical and thermal quantities determining the operating state of a furnace as a function of arc current. Operating characteristics are determined for individual furnace transformer taps. They can be determined by calculation methods, or measuring methods for working arc devices. Knowledge of high-current path parameters is also necessary to determine the electrode position regulator settings. The author has developed a method for determining the actual values of high-current path parameters based on the measurements of currents and voltages at the conclusion of electrodes with a charge, using measurement data from power quality parameters analyzers. This method has been patented and verified in real conditions. A short circuit is carried out with a simultaneous immersion of all three electrodes in molten metal when feeding the furnace with the lowest voltage, and the highest inductance in the high-current path. This is to limit the flowing short-circuit current. The electrodes are lowered in such a way that their ends are immersed in liquid metal, ensuring a complete short circuit, and then immobilized. Details of the method are presented in the publication [46].

\section{Distortion of the Voltage Curve}

The degree of arc voltage distortion has a direct effect on the furnace current shape. Distorted current flowing in the supply network causes a distorted voltage drop at the network impedance, which by subtracting from the sinusoidal supply (source) voltage causes that the supply voltage of the steel mill and steelworks is not sinusoidal. The measured arc voltage waveforms show changes in voltage shape during the melting process in the arc furnace, seen in Figure 17. In the initial phase, after the ignition of the arc, the voltage shows large stochastic changes that result from the change in the length of the arc moving along the charge. The shapes of the positive and negative semi-periods differ from each other, and their duration is different (Figure 17a). This causes both even and odd harmonics to form in the supply network. Along with the amount of molten charge under the electrodes, the arc stabilizes. The arc voltage has a rectangular shape, see Figure $17 \mathrm{~b}$. The changes are no longer as stochastic as in the initial casting period. We can talk about the periodicity of changes in the arc voltage. After melting the charge, when the arc is not yet completely covered by foamed slag, the arc voltage is similar to a triangular one, as in Figure 17c. The temperature of the molten charge, furnace atmosphere, as well as the very electrodes, increases. In the last stage of casting, the electric arc stabilizes. This is due to the fact that the arc is covered with foamed slag, which affects the thermal conditions of the furnace operation. The voltage shape is similar to a sinusoidal one, as in Figure 17d.

The arc furnace, which is a nonlinear receiver, is a source of higher harmonics. Especially in the initial phase of casting, when the arc voltage in a shape similar to a rectangular waveform occurs as both even and odd harmonics. An additional difficulty in the analysis of voltage distortion in the 
networks supplying arc devices is the impact of the load of the power system with nonlinear receivers, where the degree of distortion is variable in time, and has a waveform similar to the daily load of the power system, from Figure 18.
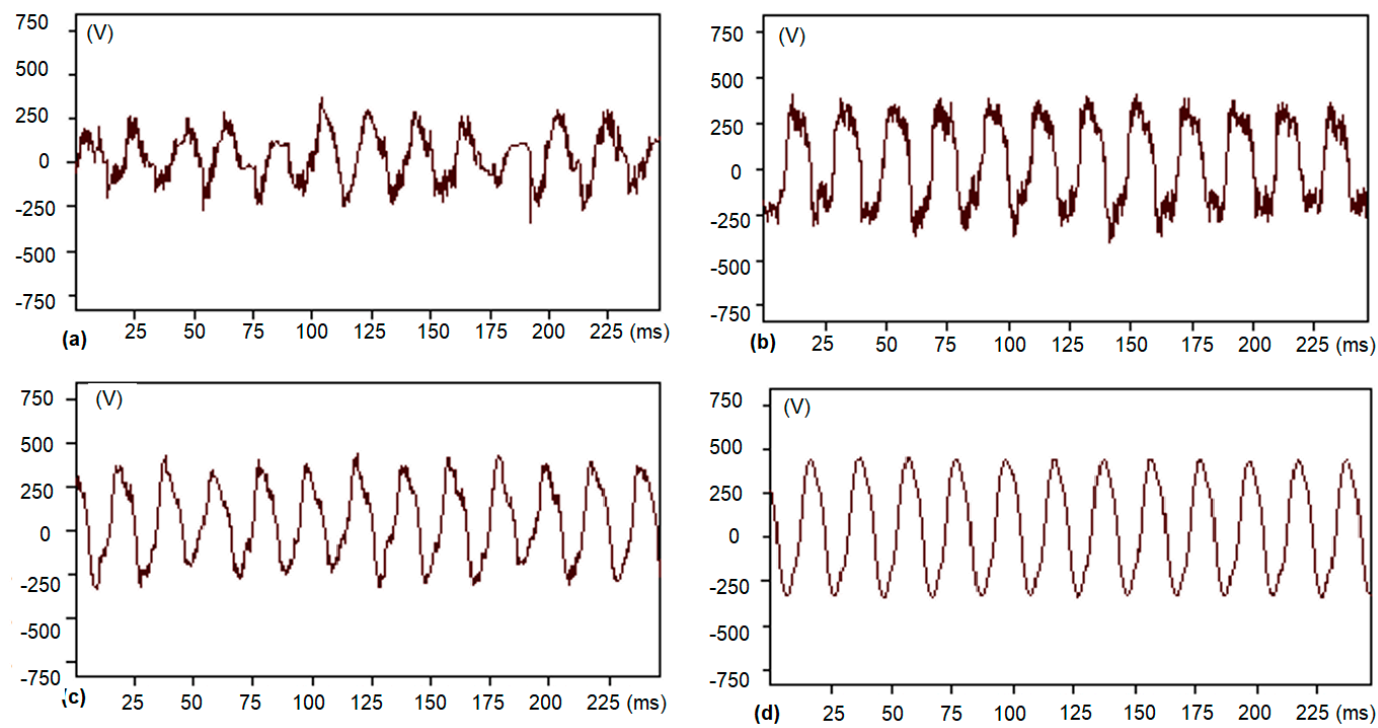

Figure 17. Waveforms of arc voltage in individual stages of smelting: (a) arc ignition; (b) start of melting the charge; (c) main melting phase; (d) final stage of smelting [58].

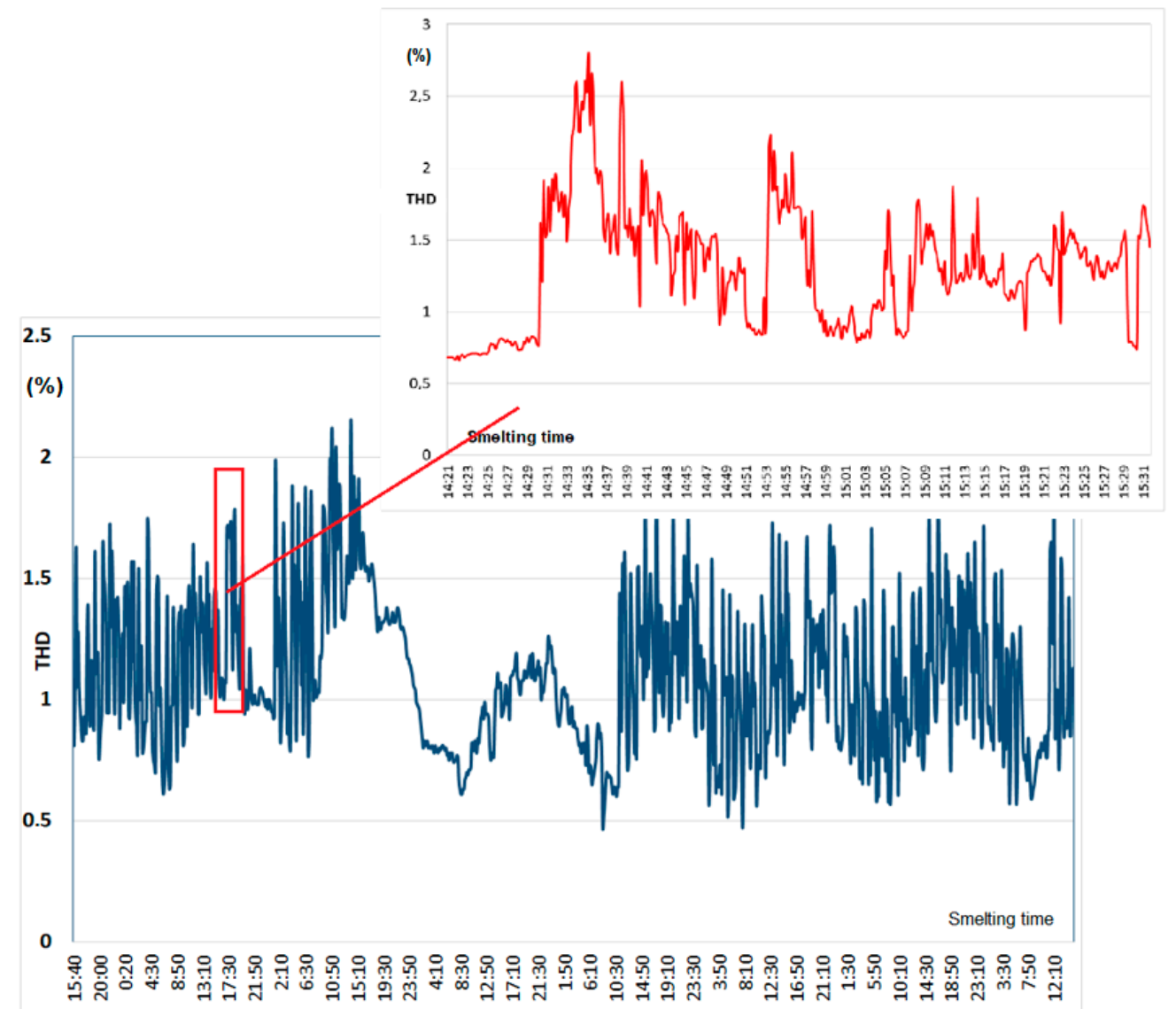

Figure 18. Changes in the total harmonic distortion (THD) coefficient measured during the week and during one melt. 
The specific nature of the work of arc furnaces causes that the values of the parameters characterizing the voltage quality change with the stages of melting the charge within the same melt. This also applies to indicators determining the supply voltage distortion, i.e. total harmonic distortion (THD) and uh. In addition, the supply voltage spectrum changes during melting. The values of individual harmonics change, with both even and odd harmonics. Figure 19 presents changes in the total THD harmonic voltage coefficient recorded during one melt (at five-second measuring intervals) and the spectrum of voltage harmonics with the arc furnace turned off (a), during scrap melting, when this THD reached its maximum value (b), and after the melting charge, before loading the next scrap bin (c). With the furnace switched off, only odd harmonics occur, with the dominant fifth harmonic being $u(5)=0.69 \%$ of the basic harmonic $(u(3)=0.09 \%, u(7)=0.06 \%)$, Figure 19 a. Turning on the furnace causes the flow of distorted current, which increases the voltage distortion of the odd harmonics: $\mathrm{u}(5)=2.17 \%, \mathrm{u}(3)=1.15 \%, \mathrm{u}(7)=0.2 \%$, and the appearance of even harmonics of respectively: $\mathrm{u}(2)=0.36 \%, \mathrm{u}(4)=0.79 \%, \mathrm{u}(6)=0.95 \%, \mathrm{u}(8)=0.30 \%$, Figure $19 \mathrm{~b}$. In the final stage of melting the first scrap basket, the voltage distortion decreases, and the content of individual harmonics is: even $\mathrm{u}(2)=0.09 \%, \mathrm{u}(4)=0.04 \%, \mathrm{u}(6)=0.03 \%, \mathrm{u}(8)=0.01 \%$, and odd $\mathrm{u}(3)=0.26 \%, \mathrm{u}(5)=1.28 \%, \mathrm{u}(7)$ $=0.49 \%, u(9)=0.02 \%$, Figure $19 \mathrm{c}$.

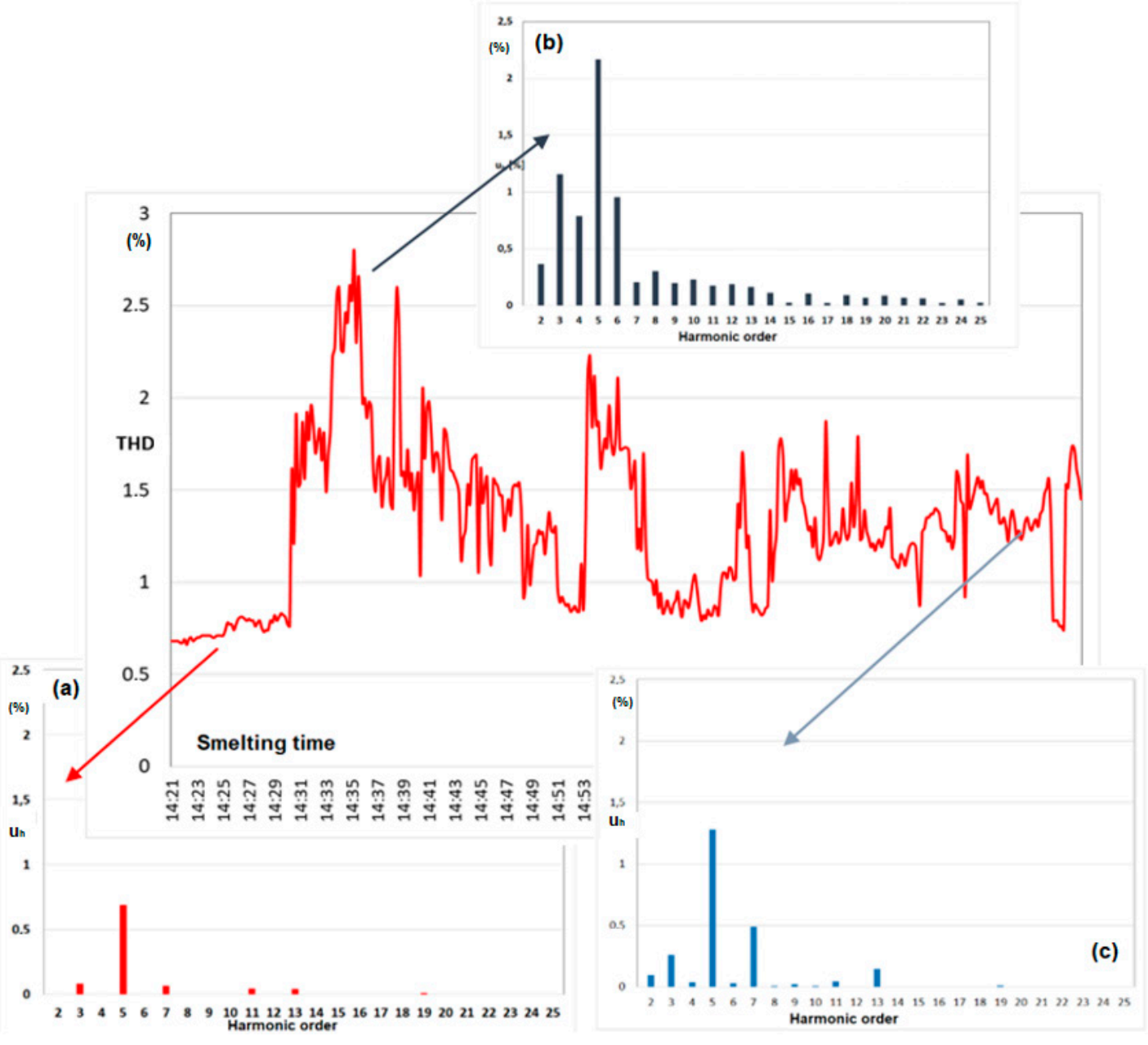

Figure 19. Changes in THD coefficient and voltage harmonic spectra in different stages of casting: (a) furnace off; (b) beginning of melting the charge; (c) molten charge.

The changing harmonics spectrum in terms of the values of individual components, as well as in order, may cause interference in the operation of the furnace installation devices. Capacitor batteries 
used to compensate the reactive power of an arc furnace are particularly at risk. Voltage increases due to resonance conditions may appear at the capacitor terminals.

For the model analysis of voltage and current distortion arising in the networks supplying arc furnaces, a single-phase equivalent circuit of an arc device with a multi-voltage model of an electric arc was proposed, as can be seen in Figure 20.

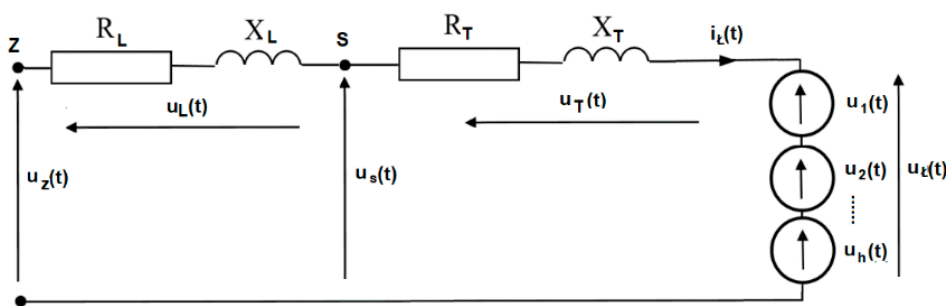

Figure 20. Single phase equivalent circuit with a multi-voltage arc model.

The multi-voltage model of the arc device was developed on the basis of analysis of the recorded real arc voltage waveforms, while the voltage changes its shape during the individual stages of melting in the arc furnace.

The multi-voltage arc model is a series connection of the voltage sources of successive harmonics. Having arc voltage waveforms recorded in industrial conditions (Figure 21a), using the fast Fourier transform (FFT), the arc voltage harmonic spectrum was determined, which allowed modeling of the arc voltage with the use of a multi-voltage model (Figure 21b). Taking into consideration the multi-voltage arc model, determined on the basis of the actual arc voltage curve $u_{\text {arc }}(t)$, voltage waveforms on the steel bus bars $u_{s}(t)$ were modeled, as in Figure 22, for two different short-circuit power ratios of the network to the furnace when the electrodes are short-circuited with the charge, respectively, 140 (Figure 22a) and 20 (Figure 22b)(similar to voltage fluctuations).
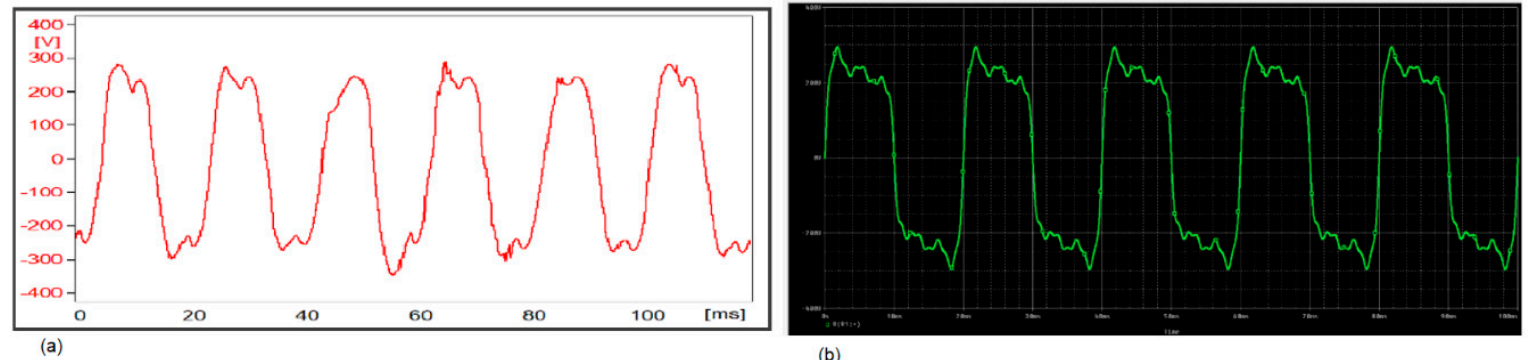

(b)

Figure 21. The waveforms of the arc voltage at the initial stage of melting: (a) measured (b) determined by a multi-voltage model.
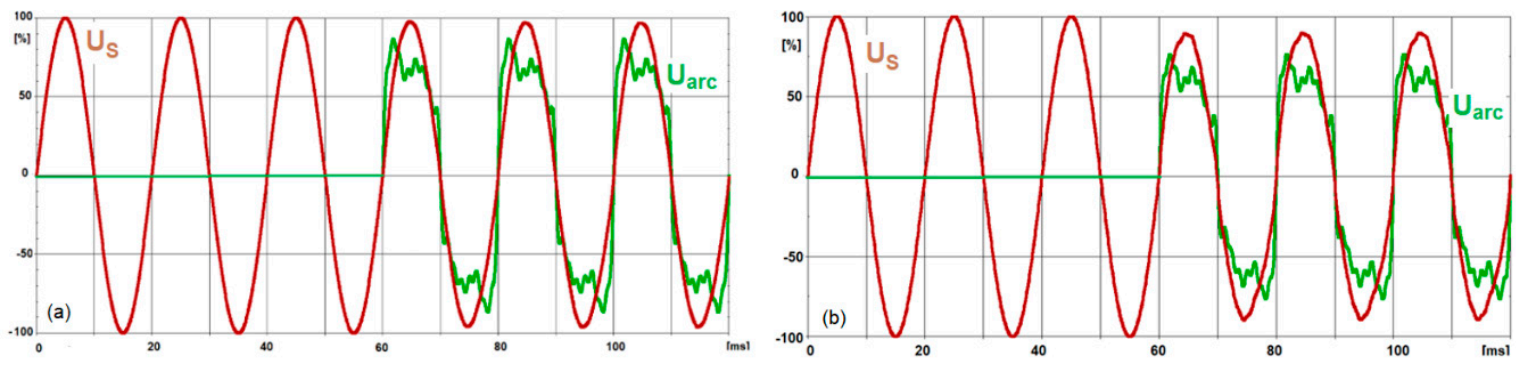

Figure 22. Waveforms of voltage on the rails of the steel plant $\mathrm{u}_{\mathrm{s}}(\mathrm{t})$ and arc voltage $u_{\mathrm{arc}}(\mathrm{t})$ for two different short-circuit powers of the steel supply network, (a) $S_{\mathrm{cc}} / S_{\mathrm{ctr}}-140$, (b) $S_{\mathrm{cc}} / S_{\mathrm{ctr}}=20$. 
The simulation of arc furnaces based on real data requires a lot of measurements, in a very difficult industrial environment, that will be representative of different power supply systems, and will include individual melts in various types of arc devices. An additional difficulty is taking into account changes in the voltage supplying the steel mill, which is influenced by other nonlinear recipients. The proposed model is a compromise between the accuracy of the mapping voltage and current distortion in networks supplying arc devices and the possibility of using it in practical applications. The multi-voltage model can be included both in dynamic models, when real arc voltage waveforms are used, as well as quasi-dynamic, in the case of theoretical waveforms (rectangle, triangle) representing the arc voltage in individual melting phases.

In the case when the arc voltage is presented by a theoretical waveform, e.g. rectangular, we have a characteristic spectral distribution - Figure 23. The amplitudes of the next odd harmonics are equal to the ratio of the amplitude of the first harmonic to the harmonic order, h, e.g., $u(3)=u(1) / 3, u(5)=$ $\mathrm{u}(1) / 5, \mathrm{u}(7)=\mathrm{u}(1) / 7, \ldots \mathrm{u}(\mathrm{h})=\mathrm{u}(1) / \mathrm{h}$. It can be assumed that in the initial phase of casting, the arc voltage takes a rectangular shape $[59,60]$.

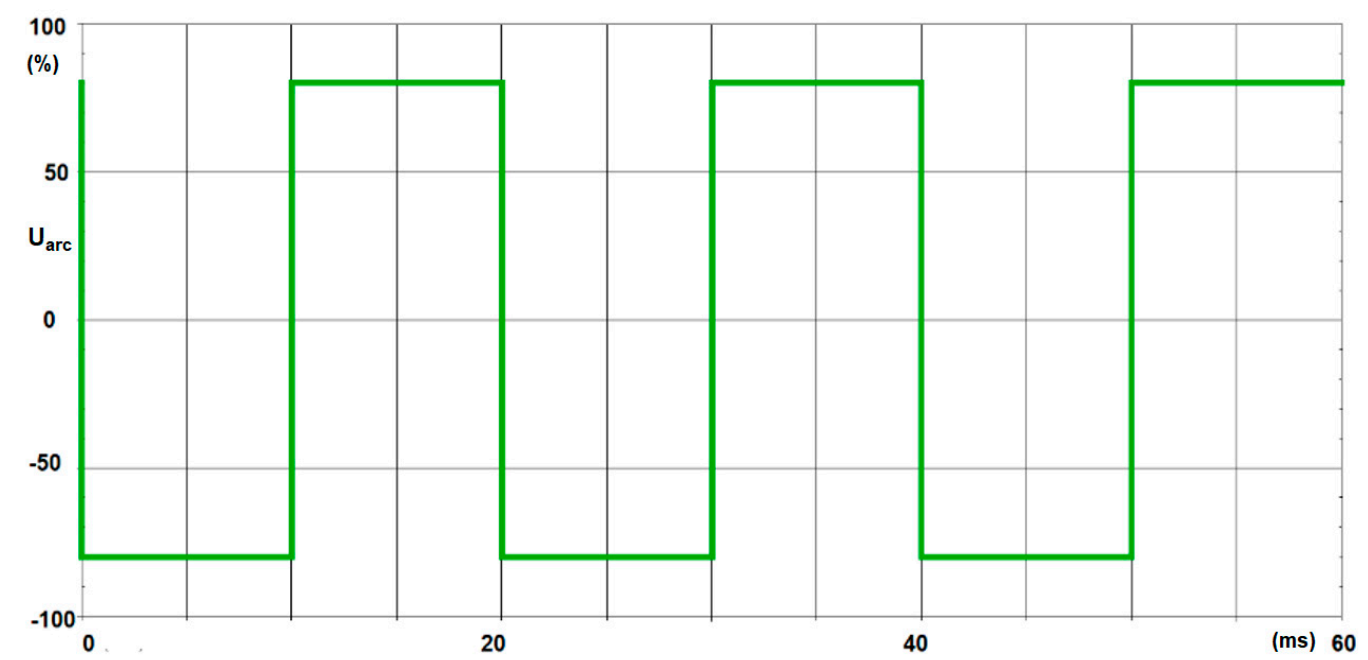

Figure 23. Waveform of a rectangular arc voltage for a multi-voltage model.

In the further stages of melting the charge, the arc voltage distortion is reduced (close to triangular) to reach a sinusoidal wave in the final phase.

Using the multi-voltage model of an arc device (Figure 24), a simulation of the influence of an arc furnace on voltage distortions in the steelworks supply network, taking into account the steel plant supply conditions, was carried out. The parameters of the network supplying the steel mill and the steel line supplying the steel mill were the same as for the voltage fluctuation analysis.

The effect of the arc furnace on the voltage distortion in the steel mains supply network increases with increasing impedance of the steel mains supply network. Figure 24 presents the harmonics spectrum and the voltage supplying the steelworks for various short circuit power supplying the steelworks at a rectangular arc voltage.

Figure 24a relates to the distortion and voltage drop at the impedance of the network supplying the steel mill, with the short-circuit power ratio of the network to the power at short circuits of the electrodes with the charge of $S_{\mathrm{cc}} / S_{\mathrm{ctr}}=140$, respectively, Figure $24 \mathrm{~b}-S_{\mathrm{cc}} / S_{\mathrm{ctr}}=20$.

Due to the fact that arc devices are characterized by significant inductive reactive power consumption, it is necessary to use reactive power compensation devices. These include capacitors connected in parallel to the furnace installation, e.g. in the station from which the furnaces are supplied. 


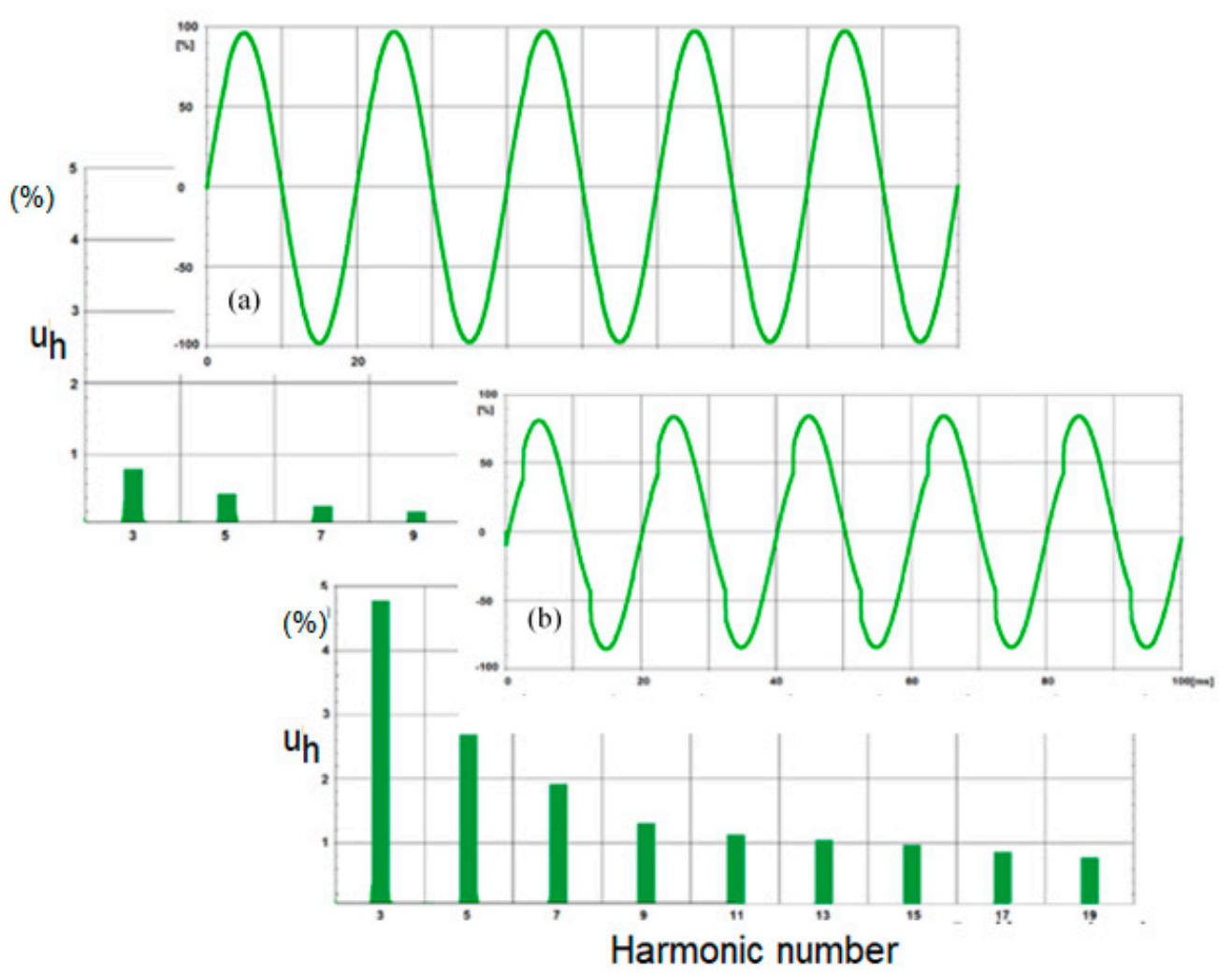

Figure 24. Waveforms and harmonics spectrum of the steel supply voltage for various short circuit power of the supply network at a rectangular arc voltage (a), change of voltage waveform and harmonics spectrum for $S_{\mathrm{cc}} / S_{\mathrm{ctr}}=140(\mathbf{b})$, change of voltage waveform and harmonics spectrum for $S_{\mathrm{cc}} / S_{\mathrm{ctr}}=20$.

Using a multi-voltage model of the electric arc, the author analyzed the impact of the attached capacitor bank on improving power conditions on steel rails. Switching on the capacitors causes distortion (during the transient state) of the current shape, as well as the increase and oscillation of the voltage supplying the furnace transformer, as in Figure 25.

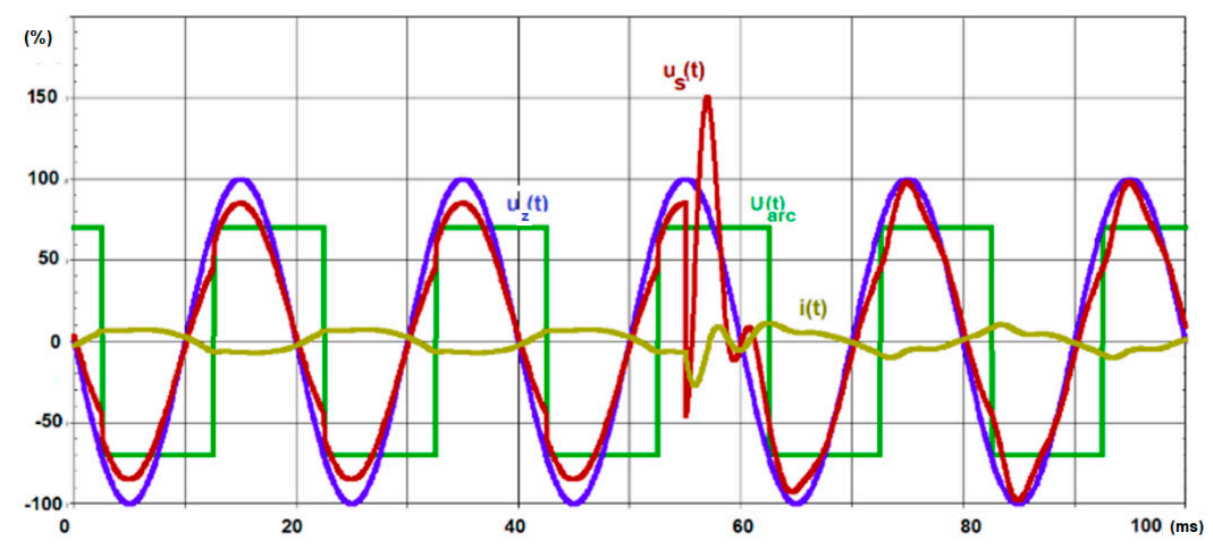

Figure 25. Waveforms of supply voltage $u_{\mathrm{z}}(\mathrm{t})$, voltage on steel busbars $u_{\mathrm{S}}(\mathrm{t})$ and voltage $u_{\operatorname{arc}}(\mathrm{t})$ and furnace current $i(\mathrm{t})$, switching on the capacitor banks.

The range of voltage changes $u_{\mathrm{s}}(\mathrm{t})$ and the duration of transients depends mainly on the parameters of the $R_{\mathrm{L}}$ and $\mathrm{X}_{\mathrm{L}}$ supply lines. 
Figure 26 shows the following waveforms: voltage supplying steelworks $u_{\mathrm{z}}(\mathrm{t})$, voltage on steel bus rails $u_{\mathrm{s}}(\mathrm{t})$ and current in the steel supply line $i(\mathrm{t})$ when switching on capacitor banks for networks with low resistance and reactance.

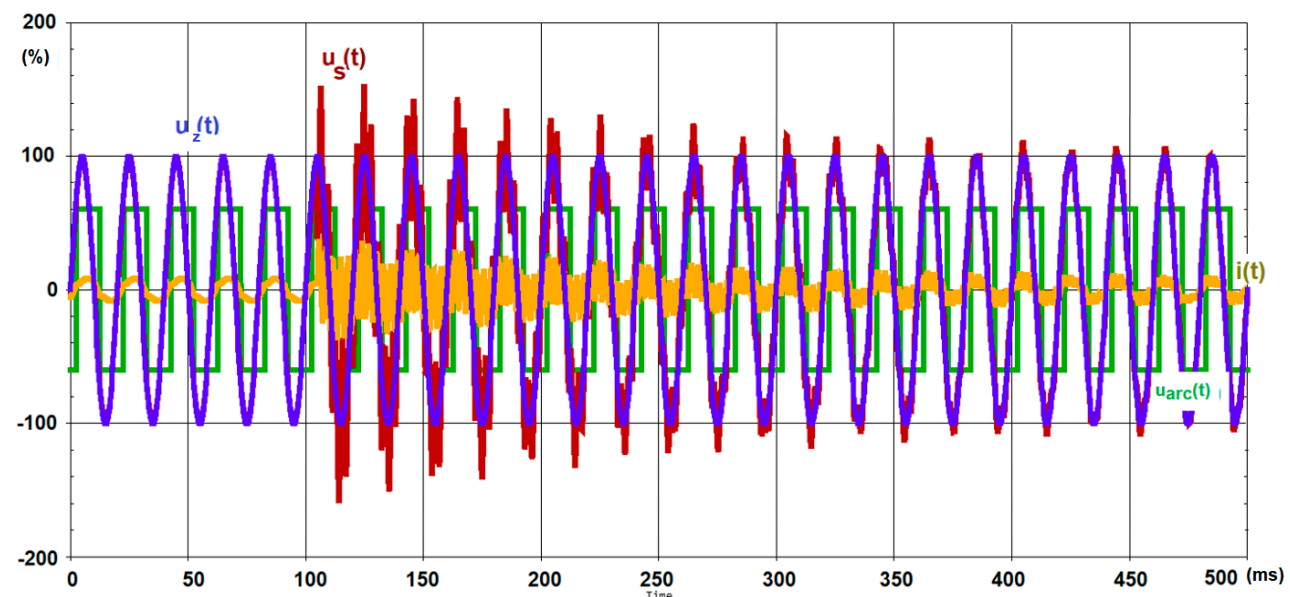

Figure 26. Waveforms of supply voltage $u_{\mathrm{z}}(\mathrm{t})$, voltage on steel busbars $u_{\mathrm{S}}(\mathrm{t})$, as well as voltage $u_{\operatorname{arc}}(\mathrm{t})$ and arc current $i(\mathrm{t})$, switching on capacitor banks (networks with high short-circuit power).

As already mentioned, in the case of worse furnace supply conditions (lower short-circuit power), there is a greater impact of the furnace on the value and distortion of the voltage supplying the steel mill.

Sudden voltage increases due to transient states occurring when switching on the capacitor banks can be limited by the use of chokes.

The proposed model takes into account changes in arc voltage amplitude and spectrum during melting. For another phase of casting, e.g. before loading another scrap bin, based on the recorded arc voltage, you can model a different arc voltage.

\section{Summary}

Based on the analysis of the measurements of indicators characterizing the quality of the supplied voltage and model tests, it can be clearly stated that the main disturbances caused by arc furnaces are voltage fluctuations. The magnitude of voltage fluctuations is primarily affected by the ratio of the short circuit power of the network to the furnace power at short circuit of the electrodes with the charge, defined as: $S_{\mathrm{cc}} / S_{\mathrm{ctr}}$. The analysis of measurement results recorded in networks supplying furnaces with different power and model tests shows that the minimum $S_{\mathrm{cc} /} S_{\mathrm{ctr}}$ value should not be less than 120-130. Then voltage fluctuations caused by arc furnaces do not cause annoying flickering of light by light sources (mainly incandescent).

According to the authors, the proposed arc model represented by the $U_{\text {arc }}$ voltage depending on the arc length allows the voltage fluctuations to be determined depending on: supply network short-circuit power, represented by $X_{\mathrm{L}}$ reactance and $R_{\mathrm{L}}$ resistance, high-current path parameters $\left(\mathrm{X}_{\mathrm{T}}\right.$, $\mathrm{R}_{\mathrm{T}}$ ) and various ranges of current changes, which correspond to different phases of casting. Furnace currents in individual stages of casting (from shorting the electrodes to the stable operation of the furnace) are represented by different histograms. At high short-circuit power of the network in relation to the installed power of arc furnaces, resistances $\left(R_{\mathrm{L}}, R_{\mathrm{T}}\right)$ in the arc supply circuit can be omitted. For the short circuit power of the network in relation to the furnace power when the electrodes are shorted with used $S_{\mathrm{cc}} / S_{\mathrm{ctr}}=140$, voltage fluctuations taking into account the resistance are $\Delta U=0.30 \%$, and without the resistance $\Delta U=0.26 \%$. Omission of resistance causes underestimation of fluctuations by $0.04 \%$. In the case of a smaller short-circuit power of the network, for which $S_{\mathrm{cc}} / S_{\mathrm{ctr}}=20$, voltage 
fluctuations with regard to resistance are $\Delta U=2.26 \%$, while excluding the resistance $\Delta U=2.16 \%$. In this case, omitting the resistance causes an underestimation of fluctuations by $0.10 \%$.

Adoption of the first harmonic arc voltage and furnace current enables us to ignore the influence of waveform distortion on the supply network parameters, mainly $X_{\mathrm{L}}$ and $X_{\mathrm{T}}$. As already mentioned, the proposed model replacing the electric arc with voltage depending on its length is a compromise between the accuracy of modeling the phenomenon and the use of the model in practical calculations.

Three-phase arc furnaces also cause current and voltage asymmetry. The short circuit power of the network also affects the magnitude of operational voltage asymmetry. The relationship between voltage asymmetry and short-circuit power is much smaller than in the case of voltage fluctuations. If the voltage fluctuations, represented by the flicker indicators, do not exceed the permissible values, then the voltage asymmetry remains at a low, acceptable level. The proposed method of determining the voltage asymmetry coefficient allows estimating the asymmetry coefficient based on known values of individual voltages. The preliminary estimation of excessive (unacceptable) asymmetry by the proposed method may form the basis for further detailed measurements.

The arc furnace, which is a nonlinear receiver, is a source of higher harmonics. Especially in the initial phase of casting, when the arc voltage with a shape similar to a rectangular waveform, generates both even and odd harmonics. An additional difficulty in the analysis of voltage distortion in networks supplying arc devices is an impact of the load of a power system including nonlinear receivers, the degree of distortion is variable in time, and has a waveform similar to a daily load of the power system. This is one of the reasons why the modeling of the influence of arc devices on voltage distortion is extremely difficult.

The data obtained as a result of measurements constitute information used to develop dynamic models of arc devices. They seem to reflect best real distortions caused by arc furnaces, e.g. distorted currents and arc voltages. However, dynamic models require the use of advanced simulation programs, which significantly limit their use in practical solutions (PSpice program was used in model tests).

In the analysis of the influence of arc devices on voltage distortion, the multi-voltage model of an electric arc was used. This model can use both ideally rectangular arc voltage, which greatly facilitates modeling, as well as data from measurements made in furnace installations. Using the proposed arc model, it is possible to determine an effect of the short circuit power of network and the melting phases on the magnitude of voltage and current distortion.

Author Contributions: Conceptualization, Z.O.; methodology, Z.O., Z.Ł.; software, Z.O.; validation, Z.O., Z.Ł.; formal analysis, Z.O., Z.Ł.; investigation, Z.O.; resources, Z.O.; data curation, Z.O.; writing-original draft preparation, Z.O.; writing—review and editing, Z.O.; visualization, Z.O.; supervision, Z.Ł.; project administration, Z.Ł.; funding acquisition Z.Ł. All authors have read and agreed to the published version of the manuscript.

Funding: This research received no external funding.

Conflicts of Interest: The authors declare no conflict of interest.

\section{References}

1. Cegielski, P.; Kolasa, A. A Computer System for Testing Static and Dynamic Properties of Welding Electricity Sources; Scientific Works of the Warsaw University of Technology: Mechanics, Warsaw, 2006; pp. 3-9. (In Polish)

2. Skrzyniecki, K.; Kolasa, A.; Cegielsk, P. Investigation of static and dynamic characteristics of the power source - arc. Weld. Rev. 2011, 6, 33-36. (In Polish)

3. Olczykowski, Z. Quasi-Static Power-Voltage Characteristics of the Arc Devic. Energy Arch. 2003, 32, 83-102. (In Polish)

4. Olczykowski, Z. Assessment of the Degree of Voltage Fluctuations in Parallel Operation of Arc Devices; AGH University of Science and Technology Press: Cracow, Poland, 2004. (In Polish)

5. Bhonsle, D.C.; Kelkar, R.B. Analyzing power quality issues in electric arc furnace by modeling. Energy 2016, 115, 830-839. [CrossRef] 
6. Bhonsle, D.C.; Kelkar, R.B. Simulation of Electric Arc Furnace Characteristics for Voltage Flicker study using MATLAB, International Conference on Recent Advancements in Electrical. Elect. Control Eng. 2011, 174-181.

7. Janabi-Sharifi, F.; Jorjani, G. An adaptive system for modeling and simulation of electrical arc furnaces. Control. Eng. Pract. 2009, 17, 1202-1219. [CrossRef]

8. Liu, Y.J.; Chang, G.W.; Hong, R.C. Curve-fitting-based method for modeling voltage-current characteristic of an ac electric arc furnace. Electric Power Syst. Res. 2010, 80, 572-581. [CrossRef]

9. Sadeghian, A.; Lavers, J.D. Dynamic reconstruction of nonlinear v-i characteristic in electric arc furnaces using adaptive neuro-fuzzy rule-based networks. Appl. Soft Comput. 2011, 11, 1448. [CrossRef]

10. Alonso, M.A.P.; Donsion, M.P. An improved time domain arc furnace model for harmonic analysis. IEEE Trans. Power Deliv. 2004, 19,367-373. [CrossRef]

11. Varadan, S.; Makram, E.B.; Girgis, A.A. A new time domain voltage source model for an arc furnace using EMTP. IEEE Trans. Power Deliv. 1996, 11, 1685. [CrossRef]

12. Horton, R.; Haskew, T.A.; Burch, R.F. A time-domain ac electric arc furnace model for flicker planning studies. IEEE Trans. Power Deliv. 2009, 24, 1450-1457. [CrossRef]

13. Montanari, G.C.; Loggini, M.; Cavallini, A.; Pitti, L.; Zaninelli, D. Arc-furnace model for the study of flicker compensation in electrical networks. IEEE Trans. Power Deliv. 1994, 9, 2026. [CrossRef]

14. Tang, L.; Kolluri, S.; McGranaghan, M.F. Voltage flicker prediction for two simultaneously operated AC arc furnaces. IEEE Trans. Power Deliv. 1997, 12, 985-992. [CrossRef]

15. Terzija, V.; Stanojevic, V. Power quality indicators estimation using robust Newton-typealgorithm. IETProc. Gen. Transm. Distrib. 2004, 151, 477-485. [CrossRef]

16. Mokhtari, H.; Hejri, M. A new three phase time-domain model for electric arc furnace using MATLAB. IEEE Asia-Pac. Transm. Distrib. Conf. Exhib. 2002, 3, 2078-2083.

17. Tseng, K.J.; Wang, Y.; Vilathgamuwa, D.M. An experimentally verified hybrid Cassie-Mayr electric arc model for power electronics simulations. IEEE Trans. Power Electron. 1997, 12, 429-436. [CrossRef]

18. Acha, E.; Madrigal, M. Power Systems Harmonics: Computer Modeling and Analysis; John Wiley \& Sons: England, UK, 2001.

19. Acha, E.; Semlyen, A.; Rajakovic, N. A harmonic domain computational package for nonlinear problems and its application to electric arcs. IEEE Trans. Power Deliv. 1990, 5, 1390-1397. [CrossRef]

20. Beites, L.F.; Mayordomo, J.G. Harmonics, Interharmonics and Unbalances of Arc Furnaces: A New Frequency Domain Approach. IEEE Trans. Power Deliv. 2001, 16, 661-668. [CrossRef]

21. Otomański, P.; Wiczyński, G. The use of a programmable AC source to generate higher harmonics in the study of electricity quality. Electr. Rev. 2015, 8, 38-41. (In Polish)

22. Samet, H.; Farjah, E.; Zahra Sharifi, Z. A dynamic, nonlinear and time-varying model for electric arc furnace. Int. Trans. Electr. Energy Syst. 2015, 25, 2165-2180. [CrossRef]

23. Emre Durna, E.; Gerçek, C.Ö.; Salor, Ö.; Ermis, M. Suppression of the Second Harmonic Subgroup Injected by an AC EAF: Design Considerations and Performance Estimation of a Shunt AP. Electronics 2018, 7, 1-16.

24. Ghiormez, L.; Panoiu, M.; Prostean, O. GUI for studying the parameters influence of the electric arc model for a three-phase electric arc furnace. In Proceedings of the IOP Conference Series: Materials Science and Engineering, Philadelphia, PA, USA, 21-23 October 2017; Volume 163, pp. 1-14.

25. Varan, M.; Uyaroglu, Y. Elimination of harmonic induced viable bifurcations with tcsc for ac-fed electric arc furnaces. J. Electr. Eng. 2012, 5, 303-309. [CrossRef]

26. Zheng, E.B.; Makram, A.A. Girgis, Effect of different arc furnace models on voltage distortion. In Proceedings of the IEEE Eighth International Conference on Harmonics Quality of Power, Athens, Greece, 14-16 October 1998; Volume 2, pp. 1079-1085.

27. Gajic, D.; Gajic, I.S.; Savic, I.; Georgieva, O.; Di Gennaro, S. Modelling of electrical energy consumption in an electric arc furnace using artificial neural networks. Energy 2016, 108, 132-139. [CrossRef]

28. Lei, W.; Wang, Y.; Wang, L.; Cao, H. A Fundamental Wave Amplitude Prediction Algorithm Based on Fuzzy Neural Network for Harmonic Elimination of Electric Arc Furnace Current. Math. Probl. Eng. 2015, 2015, 1-6. [CrossRef]

29. Yakimov, I.; Maklakov, A.; Voronin, S.; Maklakova, E. Results of Modeling Operation of the High-Speed Regulator of Non-Contact Secondary Voltage of Furnace Transformer of the High-Power Arc Steel Furnace in Constant Primary Current Mode. Procedia Eng. 2017, 206, 1853-1860. [CrossRef] 
30. Garcia-Segura, R.; Castillo, J.V.; Martell-Chavez, F.; Longoria-Gandara, O.; Ortegon, J. Electric Arc Furnace Modeling with Artificial Neural Networks and Arc Length with Variable Voltage Gradient. Energies 2017, 10, 1424. [CrossRef]

31. Ailleret, P. Determination of experimental flicker laws for their application to low voltage networks on which loads vary periodically or randomly (welders, engine starts). Bull. de la Société Française des Electriciens. 1957, 77, 257-262. (In France)

32. Hilditch, J.A.S.; Harvey, I.G. Supply voltage fluctuation due to arc furnace installations. AEI Engang. 1964, 4, 35-49.

33. Köhle, S. Ein Beitrag für statistischen Bewertung von Flicker. Elektrowärme Int. 1985, 46, $230-239$.

34. Wolska, A. Psychophysiology of Vision. Lighting Technique '96. Guide - Guide; Polish Lighting Committee, Association of Polish Electricians: Warsaw, Poland, 1996. (In Polish)

35. Brauner, G.; Hennerbichler, C. Lamp Models for Flicker Simulation and Illumination Planning; Conference Electrical Power Quality and Utilisation: Cracow, Poland, 1999.

36. Becker, C.; Elliott, M.A. Flicker-induced color and form: Interdependencies and relation to stimulation frequency and phase. Conscious. Cogn. 2006, 15, 175-196. [CrossRef]

37. Schwabe, W.E.; Kasper, R. Flicker Caused by UHP Arc Furnace using Scarp and Directly Reduced Materials; Prepared for Meeting CNBE-Beazilian National Committee-UIE: Sao Paulo, Brazil, 1976.

38. Garner, R. LED Flicker. ECS J. Solid State Sci. Technol. 2020, 9, 016017. [CrossRef]

39. Otomański, P.; Wiczynski, G.; Zając, B. Flicker Vision of Selected Light Sources. Meas. Sci. Rev. 2017, 17, 232-240. [CrossRef]

40. Sun, F.-K.; Xie, J.; Fang, Q.; Zhuo, X. Recognition algorithm for light intensity variation of LED lamps using neural network with statistics characteristics. Optik 2020, 200, 163362. [CrossRef]

41. Lodetti, S.; Azcarate, I.; Gutierrez, J.J.; Leturiondo, L.A.; Redondo, K.; Saiz, P.; Estela, J.J.M.; Romero, J.B. Flicker of Modern Lighting Technologies Due to Rapid Voltage Changes. Energies 2019, 12, 865. [CrossRef]

42. Désquilbet, G. Les Fluctuations Rapides de Tension et le Phenomene de Papillotement des Lampes (Flicker); Electricite de France-EDF, HR22/95/GD8.A: Clamart Cedex, France, 1995.

43. PN-EN 50160:2014 Parameters of the Supply Voltage in the Public Power Networks; Polish Committee of Standardizatiom: Warsaw, Poland, 2014.

44. Rozporządzenie Ministra Gospodarki z dnia 4 maja 2007 r. w sprawie szczegółowych warunków funkcjonowania systemu. Available online: http://prawo.sejm.gov.pl/isap.nsf/DocDetails.xsp?id= WDU20070930623 (accessed on 19 March 2020).

45. UIE. Guide to Quality of Electical Supply for Industrial Installations; Part 1; UIE Edition: Paris, France, 1993.

46. UIE. Guide to Quality of Electical Supply for Industrial Installations; Part 5; UIE Edition: Paris, France, 1993.

47. Olczykowski, Z. Methods of determination of the voltage fluctuations and light flicker at simultaneous operation of three-phase arc furnaces. Electr. Power Qual. Util. 2003, 9, 47-58.

48. Olczykowski, Z. Superposition of Voltage Fluctuations with Parallel Operation of arc Furnaces (in Polish: Superpozycja Wahań Napięcia Przy Pracy Pieców Łukowych). Ph.D. Thesis, Faculty of Electrical Engineering, Warsaw University of Technology, Warsaw, Poland, 2001.

49. Fortescue, C.L. Method of Symmetrical Coordi-nates Applied to the Solution of Polyphase Net-works. Trans. AlEE 1918, 37, 1027-1140.

50. EN 61000-4-30:2015-05 (EMC)—Part 4-30: Testing and Measurement Techniques—Power Quality Measurement Methods. Available online: https://webstore.iec.ch/preview/info_iec61000-4-30\%7Bed3.0. RLV\%7Den.pdf (accessed on 19 March 2020).

51. IEC 61000-2-12:2003: Compatibility Levels for Low-Frequency Conducted Disturbances and Signalling in Public Medium-Voltage Power Supply Systems. Available online: https://store.sabs.co.za/pdfpreview.php? hash=61351f6a0808385fcddd0ce84d59beef70554ee5\&preview=yes (accessed on 19 March 2020).

52. IEC 61000-2-1:1990: Description of the Environment-Electromagnetic Environment for Low-Frequency Conducted Disturbances and Signalling in Public Power Supply Systems. Available online: https://webstore. iec.ch/publication/4127 (accessed on 19 March 2020).

53. ANSI C84.1: American National Standard for Electric Power Systems and Equipment. Available online: https://www.nema.org/Standards/Pages/American-National-Standard-for-Electric-Power-Systemsand-Equipment-Voltage-Ratings.aspx (accessed on 19 March 2020). 
54. Engineering Recommendation P29: Planning Limits for Voltage Unbalance in the Unitet Kingdom, The Electricity Council. 1990. Available online: https://www.nienetworks.co.uk/documents/security-planning/erp29.aspx (accessed on 19 March 2020).

55. Gost 13109-97: Electric Energy. Electromagnetic Compatibility of Technical Equipment. Power Quality Limits in the Public Power Supply Systems. Available online: http://docs.cntd.ru/document/1200104301 (accessed on 19 March 2020).

56. Kowalski, Z. Unbalance in Electrical Power Systems; PWN (Polish Scientific Publishers): Warszawa, Poland, 1987. (In Polish)

57. Rak, J. Influence of AC ARC Furnace on Parameters of Industrial Medium-Voltage Network; Conference Electrical Power Quality and Utilisation: Cracow, Poland, 1999.

58. Olczykowski, Z. Influence of Arc Furnaces on the Power System; Kazimierz Pulaski University of Technology and Humanities: Radom, Poland, 2019. (In Polish)

59. Wasowski, A. Fluctuations de tension (flicker). Révue Générale L'electricité 1979, 3, 1-8. (In Polsih)

60. Wciślik, M. The Method of Estimating the Parameters of the Electric arc Path for the Purposes of Controlling the Electrothermal Process; Kielce University of Technology. Electricity: Kielce, Poland, 1992; p. 28.

(C) 2020 by the authors. Licensee MDPI, Basel, Switzerland. This article is an open access article distributed under the terms and conditions of the Creative Commons Attribution (CC BY) license (http://creativecommons.org/licenses/by/4.0/). 